\title{
Política Cambial, Estrutura Produtiva e Crescimento Econômico: Fundamentos Teóricos e Evidências Empíricas para o Brasil no período 1996-2012
}

\section{Exchange Rate Policy, P roductive Structure and Economic Growth: Theoretical and Empirical Evidence for Brazil in the 1996-2012 period}

Eliane Cristina de Araújo*

Samuel Costa Peres**

\begin{abstract}
Resumo: O objetivo deste artigo é analisar o perfil da estrutura produtiva brasileira entre 1996 e 2012 e de que forma ele foi impactado pelo regime de câmbio do período. A hipótese que se explicita é a de que o regime de câmbio apreciado foi prejudicial aos setores e ramos tecnologicamente mais sofisticados, favorecendo os ramos mais tradicionais e aqueles ligados às atividades primárias. Esse regime contribuiu para mudar o perfil da estrutura produtiva brasileira, provocando um processo de "desindustrialização relativa", que se reflete em variáveis do setor externo e possui importantes consequências para o crescimento econômico. Tendo em vista tal situação, a retomada do crescimento econômico sustentado só será possível mediante a reindustrialização da economia brasileira, para a qual a política cambial é a variávelchave para determinar essa mudança estrutural.
\end{abstract}

Palavras-chave: Mudança estrutural. Comércio exterior. Política cambial.

Abstract: The objective in this paper is to analyze the profile of the Brazilian productive structure between 1996 and 2012, and how it was impacted by the exchange rate regime of the period. The hypothesis is that the exchange rate regime adopted was detrimental to the sectors more technologically sophisticated, favoring the more traditional sectors and linked to primary activities. This regime has changed the profile of the Brazilian productive structure, causing a process of deindustrialization on which is reflected in the external sector variables and has important consequences for economic growth. Given this situation, the resumption of sustained economic growth can only be achieved through the re-industrialization of the Brazilian economy, for which the exchange rate policy is the key variable to determine this structural change.

Keywords: Structural change. Foreign trade. Exchange rate policy.

JEL Classification: F31; F43; L16.

\footnotetext{
* Doutora em Economia pela Universidade Federal do Rio de Janeiro (UFRJ). Professora Associada do Departamento de Economia da Universidade Estadual de Maringá (UEM). E-mail: elianedearaujo@gmail.com

* Doutorando em Economia no Programa de Pós-Graduação em Economia (PPGE) da Universidade Federal do Rio Grande do Sul (UFRGS). E-mail: scostaperes@gmail.com
} 


\section{Introdução}

Diversas análises teóricas e empíricas têm ressaltado que o nível da taxa de câmbio é um importante instrumento capaz de estimular o crescimento econômico e o processo de formação e acumulação de capital. Teoricamente, as justificativas para o impacto positivo de uma taxa de câmbio competitiva sobre o crescimento são: i) estímulo ao investimento e à poupança (WILLIAMSON, 2003; GALA 2007; BRESSER-PEREIRA, 2008, 2010), ii) benefícios para a exportação de bens não tradicionais (GALA, 2007; RODRIK, 2004), iii) aumento da produtividade (DOLLAR, 1992; POPOV; POLTEROVICH, 2002), iv) compensação às falhas de mercado e contratuais (RODRIK, 2008), e v) estímulo às elasticidades-renda das exportações (BARBOSA-FILHO, 2006; OREIRO, NAKABASHI; SOUZA, 2010). Esta relação teórica recebe respaldo empírico de diversos estudos como Dollar (1992); Razin e Collins (1997); Easterly (2001); Frenkel (2004); Aguirre e Calderón (2005) e Rodrik (2008).

Nessa discussão, é importante destacar também como variações na política cambial podem determinar as mudanças estruturais nas economias, entendidas como a reorganização da estrutura produtiva e seus reflexos na especialização do comércio exterior de um país.

No que tange à estrutura produtiva brasileira, o período pré-liberalização comercial caracterizava-se por plantas estabelecidas sob as políticas econômica e industrial associadas ao modelo de industrialização substitutiva de importações, cuja estratégia pressupunha um elevado grau de proteção à indústria. Todavia, sem sua indústria haver alcançado a fronteira tecnológica, o Brasil se reinsere no cenário internacional com fortes desvantagens competitivas em setores estratégicos como o intensivo em ciências e tecnologia. Sujeito, no plano interno, a um ambiente macroeconômico adverso (taxas muito altas de juros, tendência à apreciação cambial, ausência de políticas industriais e setoriais consistentes, déficit em infraestrutura de transportes, etc.), a reação do parque produtivo doméstico foi nitidamente defensiva, orientando-se pela sobrevivência diante das incertezas crescentes.

No entanto, seguindo autores como Rosenstein-Rodan (1943), Prebisch (1949), Lewis (1954) e Furtado (1961), além de Kaldor (1966), entende-se que as estruturas produtivas e os padrões de especialização são cruciais para o processo de crescimento econômico dos países em desenvolvimento, de modo que o crescimento de longo prazo tende a estar associado a uma estrutura produtiva baseada em produtos de alta tecnologia, caracterizados por maiores benefícios de aprendizagem e efeitos spillover, além de serem mais dinâmicos no comércio mundial e possuírem maior capacidade de indução do crescimento da produtividade a médio e longo prazo. 
Posto isso, o objetivo deste artigo é analisar o perfil da estrutura produtiva brasileira entre 1996 e 2012 e de que forma ele foi impactado pelo regime de câmbio do período. A hipótese que se explicita é a de que o regime de câmbio apreciado foi prejudicial aos setores e ramos tecnologicamente mais sofisticados, favorecendo os ramos mais tradicionais e aqueles ligados às atividades primárias. Esse regime mudou o perfil da estrutura produtiva brasileira, provocando um processo de desindustrialização relativa, que se reflete em variáveis do setor externo e possui importantes consequências para o crescimento econômico. Tendo em vista tal situação, a retomada do crescimento econômico sustentado só será possível mediante a reindustrialização da economia brasileira, para a qual a política cambial é uma variável-chave para determinar essa mudança estrutural.

Em face ao objetivo proposto, além desta introdução e das considerações finais, este artigo está organizado em mais cinco seções. A primeira discute a relação entre estrutura produtiva e crescimento econômico. A segunda trata do perfil de especialização da indústria brasileira. A terceira discute os reflexos da estrutura produtiva brasileira sobre o setor externo. Na sequência, a quarta seção relaciona a evolução da indústria brasileira com a trajetória da taxa de câmbio, a qual é seguida de algumas experiências internacionais de utilização da taxa de câmbio como forma de estimular o setor industrial.

\section{Especialização Produtiva e Crescimento Econômico: Fundamentos Teóricos e Empíricos}

A partir de uma revisão da literatura sobre o tema, o objetivo desta seção é investigar téorica e empiricamente a relação entre taxa de câmbio, estrutura produtiva e crescimento econômico. Inicialmente, discutem-se os fundamentos teóricos e, em seguida, são apresentadas evidências empíricas acerca dessa relação.

\subsection{Fundamentos Teóricos}

Uma abordagem para o problema do crescimento é atribuída aos teóricos do lado da demanda, seguidores das ideias de Keynes e que estenderam a sua análise (de curto prazo) para a problemática do crescimento econômico. Esses autores se preocuparam em investigar, particularmente, como a insuficiência de demanda efetiva pode resultar de várias fontes e, com isso, causar um nível de investimento abaixo do requerido, emperrando o processo de crescimento.

Iniciando por Kaldor (1966), as contribuições do autor foram motivadas pela investigação sobre as causas do crescimento mais lento do Reino Unido, comparativamente a outras economias capitalistas desenvolvidas, cujos estudos levaram a elaboração de um conjunto de leis que ficaram conhecidas como leis de Kaldor. 
Derivadas de testes econométricos, essas leis buscavam explicar, através de fatos estilizados, as dinâmicas de crescimento nas economias capitalistas, dando ênfase às diferenças entre as taxas de crescimento e suas causas.

A primeira lei de Kaldor destaca que existe uma correlação positiva entre o crescimento da produção manufatureira e o crescimento do PIB. A segunda lei, conhecida como lei de Verdoorn, observa que existe uma forte correlação entre o crescimento da produção manufatureira e o crescimento da produtividade no setor manufatureiro, como resultado de rendimentos estáticos e dinâmicos de escala. A terceira lei enfatiza a existência de correlação entre expansão do setor manufatureiro e aumento da produtividade fora desse setor, em decorrência dos rendimentos decrescentes da agricultura e atividades menores que fornecem mão de obra ao setor industrial.

As explicações para as referidas leis devem-se a duas argumentações básicas. A primeira argumentação é a de que existem rendimentos crescentes à escala na indústria, tanto estáticos, quanto dinâmicos. Os rendimentos crescentes à escala estáticos referem-se ao tamanho e à escala das unidades de produção e estabelecem que variações dos insumos utilizados, equipamentos etc., conduzem ao aumento mais que proporcional na produção. Os rendimentos crescentes à escala dinâmicos, por sua vez, são aqueles obtidos pelo progresso tecnológico, pelas rotinas de aprendizagem e por economias externas à produção. Tais fatores fazem com que o aumento da produção no setor industrial exerça um efeito positivo sobre o crescimento do produto total da economia.

Em relação à segunda argumentação, Kaldor discute que, à medida que a economia vai avançando em seu processo de desenvolvimento, com a expansão da produção industrial, tem-se o aumento da demanda por recursos e mão de obra, que é obtida de setores como a agricultura, onde há frequentemente desemprego flagrante ou disfarçado, de tal modo que a transferência desses recursos para o setor manufatureiro não causa redução na produção; pelo contrário, verifica-se o crescimento da produção nos dois setores, pelo fato da produtividade crescer dentro e fora da manufatura.

Os estudos de Kaldor consolidaram a ideia de que a indústria de transformação é o setor dinâmico por excelência, o motor do crescimento econômico. Num primeiro momento, o setor industrial é essencial para o crescimento do produto e da produtividade total da economia e sua expansão é determinada pela demanda proveniente do setor agrícola. Porém, à medida que a economia já se encontra em estágio de desenvolvimento mais avançado, o setor industrial tem papel relevante a cumprir, com o aumento das exportações (THIRLWALL, 2005). Essa pode ser considerada a quarta lei de Kaldor, ou ainda, a lei Kaldor-Thirlwall.

Dando continuidade a essas ideias, Thirlwall (1979) destaca que, quando se trata de economias abertas, a restrição relevante é imposta pelo balanço de 
pagamentos, pois, à medida que o país vai crescendo, ele passa a necessitar de importações, as quais devem ser custeadas pelas receitas obtidas com as exportações. Se isso não ocorrer, o país pode esbarrar em limitações no seu balanço de pagamentos e precisará reduzir o nível da demanda doméstica, desencorajando o investimento, o progresso tecnológico e a produtividade, abortando o processo de crescimento tão logo ele tenha iniciado.

Por essa razão, Thirlwall (1979) elaborou um modelo no qual concluiu que a taxa de crescimento que um país pode alcançar sem incorrer em desequilíbrios no balanço de pagamentos é igual à taxa de crescimento das exportações, dividida pela elasticidade-renda da demanda por importações. Dentre as implicações principais do modelo de Thirlwall está o fato de que a superação da restrição imposta pelo balanço de pagamentos, com a consequente viabilização de uma maior taxa de crescimento, pode ser propiciada por meio de políticas de estímulo ao aumento da elasticidade-renda das exportações, concomitantemente à redução da elasticidade-renda das importações. ${ }^{1}$

Nesse sentido, Ocampo (2005) discute que a dinâmica setorial desempenha um papel central na tradição estruturalista do pensamento econômico, segundo a qual o crescimento é consequência de uma administração bem-sucedida de transformação dinâmica das estruturas de produção. Mais especificamente, a industrialização, na tradição estruturalista, desempenha um papel importante em uma economia autônoma, tanto por causa de sua centralidade na criação de ligações intersetoriais, que podem levar maiores estímulos endógenos ao crescimento, como por representar uma fonte de bens de capital produzidos localmente e de tecnologia.

Nesse sentido, o autor aponta que as transformações das estruturas de produção e o papel dos padrões de especialização são cruciais para o entendimento do processo de crescimento econômico dos países em desenvolvimento, de forma que o crescimento a longo prazo pode ser visto como uma sequência de surtos de crescimento setoriais resultantes de processos de inovações e de transformações estruturais de produção por eles induzidas. Historicamente, esse processo tem se relacionado a políticas de substituição de importações e/ou de promoção das exportações.

A estrutura produtiva de uma economia se reflete em seu comércio com o resto do mundo, assim, exportações de produtos intensivos em tecnologia e diferenciados evidenciam uma estrutura baseada em manufaturados que possuem maior potencial de inovação tecnológica e ganhos de produtividade. Já a concentração das expor-

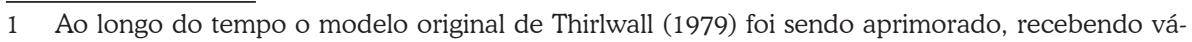
rias contribuições como: i) Thirlwall e Hussain (1982), que incorporaram os fluxos de capitais no modelo; ii) Moreno-Brid (1998-1999), que redefiniram o modelo a fim de garantir uma trajetória sustentada de acumulação de dívida; iii) Barbosa-Filho (2001) que propôs uma taxa estável para a relação dívida/PIB e a consideração do pagamento de juros e, finalmente; iv) Moreno-Brid (2003), que reformula o modelo para levar em conta explicitamente o pagamento de juros da dívida e a estabilidade da relação dívida/PIB. 
tações em setores primários ou produtos industriais intensivos em recursos naturais evidencia uma estrutura produtiva menos dinâmica.

Quanto às estratégias exportadoras, Ocampo e Parra (2006) acrescentam que os países em desenvolvimento podem se concentrar em uma das duas estratégias: aumentar o market share nos setores em que possuem uma posição estabelecida ou diversificar a produção de bens com tecnologia superior. A primeira estratégia está amplamente disponível, já a segunda pode estar disponível apenas para um número limitado de países em desenvolvimento. Isto é particulamente verdadeiro para as exportações de alta tecnologia, nas quais as oportunidades podem estar sujeitas aos efeitos de aglomeração. Oportunidades para a produção de bens primários e intensivos em recursos naturais estão mais amplamente disponíveis, mas o dinamismo dos mercados internacionais é limitado.

De acordo com Lall (2000), diferentemente da teoria econômica tradicional, a realidade mostra que o desempenho exportador dos países em desenvolvimento é bastante heterogêneo, visto que apenas um pequeno número de países está sendo bem-sucedido em expandir seus ganhos com as exportações e melhorar a qualidade dos produtos exportados. A grande maioria dos países está estagnada em termos de ganhos de comércio e avanço tecnológico nos produtos que exporta.

Lall (2001) acrescenta que as estruturas de exportação são path-dependent, o que tem implicações importantes para o crescimento e desenvolvimento econômico com os produtos de alta tecnologia, tendo maiores benefícios em termos de aprendizagem e efeitos spillover, além de serem mais dinâmicos no comércio mundial. Palma (2004) expressa opinião semelhante baseado na capacidade diferenciada que os produtos de baixa versus os produtos de alta tecnologia têm na indução do crescimento da produtividade a médio e longo prazo na economia como um todo, bem como seu relativo dinamismo no comércio mundial.

É nesse contexto de mudança estrutural, dinamismo das exportações e crescimento econômico que aparece como variável relevante a taxa de câmbio. Seguindo a abordagem keynesiana-estruturalista dos modelos demand led, o crescimento dos países em desenvolvimento seria fortemente impulsionado pela manutenção da taxa real de câmbio em níveis competitivos. Os argumentos, desenvolvidos formalmente em trabalhos como Rowthorn (1981), Dutt (1984, 1990), Taylor (1985) e Bhaduri e Marglin (1990), são de que a taxa real de câmbio exerce um efeito positivo sobre o desempenho das exportações e cria incentivos à produção de bens substitutos às importações, o que tende a provocar um aumento da demanda agregada e, assim, da produção e do emprego no médio-longo prazo. Ademais, a taxa de câmbio influenciaria a distribuição funcional da renda, o padrão de especialização da economia e, desse modo, o tamanho e o dinamismo do setor manufatureiro.

Nesse sentido, Gala e Libânio (2011) observam que, dado que uma taxa de câmbio competitiva possa ser um estímulo à especialização setorial, a manutenção 
de uma taxa de câmbio sobreapreciada tende, por sua vez, a bloquear o canal de aumento de produtividade associado ao desenvolvimento dos setores industriais. Em decorrência dessa apreciação, a lucratividade desses setores diminui, sua participação na produção agregada se reduz, enquanto aumenta a de bens não manufaturados, especialmente aqueles ligados à produção de commodities e/ou de bens não comercializáveis.

Ainda que no modelo de Thirlwall (1979) exista uma relação direta entre a taxa de crescimento do produto de longo prazo e a razão entre as elasticidades-renda da demanda por exportações e importações, os trabalhos de Pasinetti $(1981,1993)$ demonstram que mudanças na estrutura de produção provocam modificações na trajetória de crescimento, uma vez que cada setor possui uma capacidade particular (diferentes elasticidades) de aproveitar o aumento do produto. Essas diferenças setoriais de elasticidade, incorporadas num modelo de crescimento de restrição do balanço de pagamentos análogo ao de Thirlwall, tal como em Araújo e Lima (2007), resultam num modelo multissetorial em que a taxa de crescimento da renda per capita de um país é diretamente proporcional à taxa de crescimento das suas exportações (dada pela elasticidade-renda da demanda setorial multiplicada pela taxa de crescimento da economia mundial) e inversamente relacionada com as elasticidades-renda da demanda por importações setoriais, sendo ambas as elasticidades ponderadas pela participação relativa dos setores na pauta de comércio. Nesse caso, mudanças na composição da demanda ou na estrutura produtiva não captadas pelas elasticidades, mas refletidas na participação de cada setor nas exportações ou importações agregadas, são importantes para o crescimento.

A taxa de câmbio, por seu turno, embora não altere a elasticidade-renda de cada setor, modifica a elasticidade-renda agregada na medida em que o seu patamar afeta o volume e a participação de exportações daqueles produtos cuja margem de lucro é mais estreita, notadamente os manufaturados de elevado conteúdo tecnológico no caso dos países em desenvolvimento, que não possuem vantagens comparativas em sua produção. Ao mesmo tempo, o volume e participação de importações de manufaturados também são influenciados pelas oscilações da taxa real de câmbio, dado que a parcela da demanda interna por manufaturados atendida pelas importações oscila em função da mudança de preços relativos entre os produtos produzidos internamente e externamente. Assim, conforme Oreiro, Basílio e Souza (2013), a manutenção de um câmbio desvalorizado é capaz de provocar a alteração da estrutura produtiva ao direcionar recursos para o setor produtivo de bens manufaturados para exportação, promovendo mudança estrutural na economia, afetando as elasticidades-renda agregadas das exportações e importações e possibilitando a realização do catching-up frente aos países desenvolvidos.

Em suma, admitindo-se que uma taxa de câmbio competitiva possa ser um estímulo à especialização setorial, e considerando que pelo enfoque multissetorial os pa- 
íses podem crescer a taxas maiores, atendendo às restrições de equilibrio do balanço de pagamentos, a partir de alterações na participação relativa de cada setor na pauta de comércio exterior, a política cambial surge então como ferramenta fundamental numa estratégia de mudança estrutural que vise a um crescimento econômico vigoroso e sustentado no longo prazo.

\subsection{Evidências Empíricas}

Empiricamente, Ocampo e Parra (2006) esclarecem sobre a existência de correlação entre padrões de especialização e crescimento econômico em países em desenvolvimento. Suas evidências empíricas mostram que o crescimento econômico no mundo em desenvolvimento está negativamente correlacionado com a dependência contínua das exportações de bens primários e intensivos em recursos naturais; positivamente correlacionado com a diversificação em direção a produtos manufaturados de média e alta tecnologia, e sem nenhum padrão claro quando se trata de sua correlação com as exportações de produtos manufaturados de baixa tecnologia. Existem, no entanto, diferenças significativas no desempenho ao redor do padrão médio.

Continuando a apresentar evidências empíricas, os autores destacam que um olhar mais atento para essa questão percebe que a maioria dos países que não conseguiram aumentar seu market share nos mercados mundiais é exportadora de bens primários ou manufaturas intensivas em recursos naturais, e todos tiveram baixo crescimento ou contração do PIB per capita. As excessões da amostra de 96 países analisados são Chile, Omã, Uganda e Egito, que ao utilizar uma estratégia baseada em recursos naturais obtiveram taxas de crescimento per capita superiores a dois por cento entre 1980-2002.

Outros países que registraram rápidas taxas de crescimento mesclaram essa estratégia com a produção de manufaturas de baixa tecnologia (Vietnã, Ilhas Maurício, Índia, Indonésia, Sri Lanka e Myanmar) ou de alta tecnologia (Costa Rica, que teve, em qualquer caso, uma taxa muito menor do crescimento). Há também países (Cabo Verde, República Dominicana, Nepal e Tunísia) que obtiveram rápido crescimento mediante um padrão de especialização baseado em manufaturas de baixa tecnologia ou, como citado anteriormente, misturando-o com produtos intensivos em recursos naturais. Mas, a maioria dos países em desenvolvimento que apresentou acelerado crescimento ampliou seu market share nas exportações de média e alta tecnologia. Finalmente, há uma diferença significativa na capacidade de crescimento dos países asiáticos vis-à-vis os países da América Latina (Costa Rica e México), Europa Central (Hungria e Polônia) e Oeste da Ásia (Turquia). Tal desempenho, para Ocampo e Parra (2006), pode estar relacionado às exportações de alta tecnologia dominantes nos asiáticos. 
Em síntese, os autores apresentam evidências de que há grande diferença nas taxas médias de crescimento a favor dos países que passam por uma transformação dos padrões de especialização em direção a mais exportações de alta tecnologia quando comparados àqueles especializados em setores intensivos em recursos naturais, mesmo quando os últimos conseguem aumentar seu market share nesses setores. Mostraram, ainda, que os países que baseavam suas exportações em produtos primários e industriais intensivos em recursos naturais em 2002 não cresceram nas duas décadas anteriores, ao passo que os que mais cresceram haviam se especializado em recursos não naturais ou apenas em produtos de alta tecnologia. Já a combinação das exportações de recursos naturais com não naturais, bem como a especialização em produtos de baixa tecnologia, são casos intermediários entre esses dois extremos.

Embora as conclusões apresentadas não sejam necessariamente encorajadoras para todos os países em desenvolvimento, elas indicam que qualquer país que queira acelerar o crescimento deve aprender com as Novas Economias Industrializadas da Ásia, realizando esforços corporativos para atualizar constantemente as capacidades de produção e exportação. Apesar da diversificação das exportações em média e alta tecnologia não ser viável para muitos países em desenvolvimento, elas podem implicar oportunidades para alguns deles.

Portanto, no longo prazo, os países não devem hesitar em entrar no processo de aprendizagem em suas exportações, tendo sempre em mente o objetivo de atualizar as capacidades de exportação e evitar a estagnação em torno de produtos primários e, talvez, até mesmo fábricas intensivas em trabalho. Destaque-se também que, a partir da perspectiva de crescimento setorial, a convergência de renda entre países não industrializados e industrializados não é um resultado natural da dinâmica econômica, requerendo, desse modo, a intervenção do Estado via políticas econômicas que estimulem setores estratégicos.

Nesse contexto, trabalhos como Araújo, Bruno e Pimentel (2012), Cimoli, Fleitas e Porcile (2013), Rapetti, Skott e Razmi (2012) e Rodrik (2008) evidenciam o papel relevante da política cambial ou da taxa de câmbio enquanto instrumento indutor dessa mudança estrutural em direção a setores produtivos tecnologicamente mais sofisticados e, por conseguinte, de uma diversificação e maior dinamismo das exportações. Em particular, Rodrik (2008) encontra duas regularidades empíricas. Primeiro, a desvalorização cambial possui um efeito positivo direto no tamanho relativo do setor de bens comercializáveis, especialmente aqueles relacionados às atividades industriais. Segundo, os efeitos da taxa real de câmbio no crescimento operam, ao menos em parte, por meio dessas mudanças associadas ao tamanho relativo do setor de bens comercializáveis. Ou seja, países em que a desvalorização induz um direcionamento dos recursos ao setor de bens comercializáveis - principalmente nas atividades industriais - crescem mais rapidamente. 
Cimoli, Fleitas e Porcile (2013), por sua vez, encontram evidências de que uma taxa real de câmbio depreciada possui efeitos significativos de diversificação das exportações, e essa diversificação conduz a um aumento da intensidade tecnológica dos bens exportados. Ademais, os resultados econométricos evidenciam a existência de path-dependence, i.e., há fatores endógenos que reproduzem o padrão dominante de especialização. Isso implica que apenas com políticas ativas é possível superar as forças que perpetuam as restrições estruturais ao crescimento. Nesse sentido, uma taxa real de câmbio depreciada pode ser um ponto de partida para impulsionar as exportações que, via retornos crescentes, induz a um upgrading tecnológico na estrutura exportadora. Mas, para que esse upgrading avance e se sustente, o câmbio competitivo deve ser combinado com políticas industriais e tecnológicas ativas.

\section{Perfil da Estrutura Produtiva Brasileira}

Esta seção analisa a evolução recente da estrutura produtiva brasileira, e procura identificar qual o padrão de especialização do país. Em primeiro lugar, é interessante observar que a produção na indústria de transformação tem apresentado, historicamente, um menor dinamismo em relação à produção no setor industrial extrativo. No período 1996-2012, a indústria de transformação cresceu a taxas médias bastante inferiores às observadas na indústria extrativa. Nesse período, a primeira cresceu à taxa média anual de 1,8\%, enquanto a segunda cresceu à média de $6,7 \%$. Como resultado, o crescimento médio da indústria geral no período foi de apenas $2,2 \%$, haja vista que a representatividade da indústria de transformação no valor da produção total é bastante superior à indústria extrativa. ${ }^{2}$

Por outro lado, utilizando o conceito de valor da transformação industrial (VTI), ${ }^{3}$ constata-se que, desde 1996, o peso relativo da indústria de transformação no VTI seguiu tendência de queda, cedendo espaço para a indústria extrativa, conforme Gráfico 1.

2 Dados divulgados pelo IBGE - CNT (2013). Na análise em questão, foram consideradas as médias dos índices quantum dessazonalizados e anualizados, sendo a base 2002.

3 Conforme a definição do IBGE, o valor da transformação industrial (VTI) corresponde à diferença entre o valor bruto da produção industrial (VBPI) e o custo com as operações industriais (COI). 
Gráfico 1 - Composição do VIT por setor de atividade - Brasil: 1996-2011 (em \%)

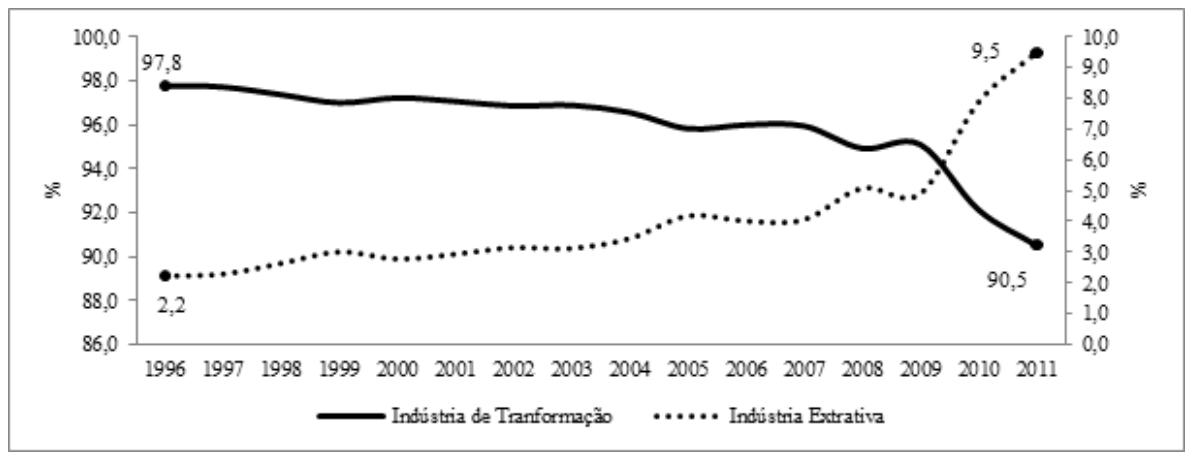

Fonte: Elaboração própria a partir de IBGE-PIA (2013).

No intuito de verificar mudanças na estrutura produtiva, os diversos segmentos industriais e não industriais podem ser classificados segundo a tecnologia empregada na produção, conforme a tipologia sugerida pela Organization for Economic Cooperation and Development (1987), inspirada pela taxonomia clássica de Pavitt (1984). Esta taxonomia baseia-se em uma análise de fatores específicos dentro de setores, tais como os regimes tecnológicos dominantes, as características estruturais, a origem da inovação, os tipos de resultados, as formas de apropriação e possibilidades de diversificação tecnológica. Cada tipo de tecnologia associa-se ao fator principal que estabelece o posicionamento competitivo das empresas e setores no curto e no longo prazo, como segue:

a) Produtos primários: agrícolas, minerais e energéticos;

b) Indústria intensiva em recursos naturais: o fator principal de competitividade é o acesso a recursos naturais abundantes existentes no país;

c) Indústria intensiva em trabalho: o fator mais relevante de competitividade é a disponibilidade de mão de obra com custos reduzidos relativamente a outros países;

d) Indústria intensiva em economias de escala: o principal fator de competitividade é a possibilidade de explorar ganhos por produzir em grande escala;

e) Indústria de tecnologia diferenciada: o principal fator de competitividade é a adaptação do produto à demanda, de padrões diversos;

f) Indústria intensiva em ciência ou PEBD: o principal fator de competitividade é a rápida aplicação dos avanços científicos às tecnologias industriais.

Basicamente, os setores intensivos em escala, tecnologia diferenciada e ciência, ao possuírem, salvo exceções, maior intensidade na relação capital/trabalho e maior sofisticação tecnológica em seus processos produtivos, têm maior capacidade de promover efeitos de encadeamento para frente e para trás e, portanto, de 
gerar maiores efeitos multiplicadores de renda e emprego, bem como de produzir e difundir inovações para o restante da economia. Por outro lado, os setores intensivos em recursos naturais e trabalho têm maior capacidade de gerar empregos diretos. Nesse sentido, diversas pesquisas recentes têm evidenciado que os setores com tecnologia diferenciada e baseada em ciência aparecem, particularmente, como os principais determinantes da maximização dos ganhos de produtividade nas economias e pela sustentação do crescimento econômico no longo prazo. ${ }^{4}$

Com base na tipologia descrita anteriormente, o Gráfico 2 informa sobre a evolução da estrutura produtiva da economia brasileira entre 1996-2011, conforme a participação dos setores industriais com tecnologia no VTI (desconsideram-se, portanto, os produtos primários). ${ }^{5}$

Gráfico 2 - Composição setorial do VTI - Brasil: 1996-2011 (em \%)

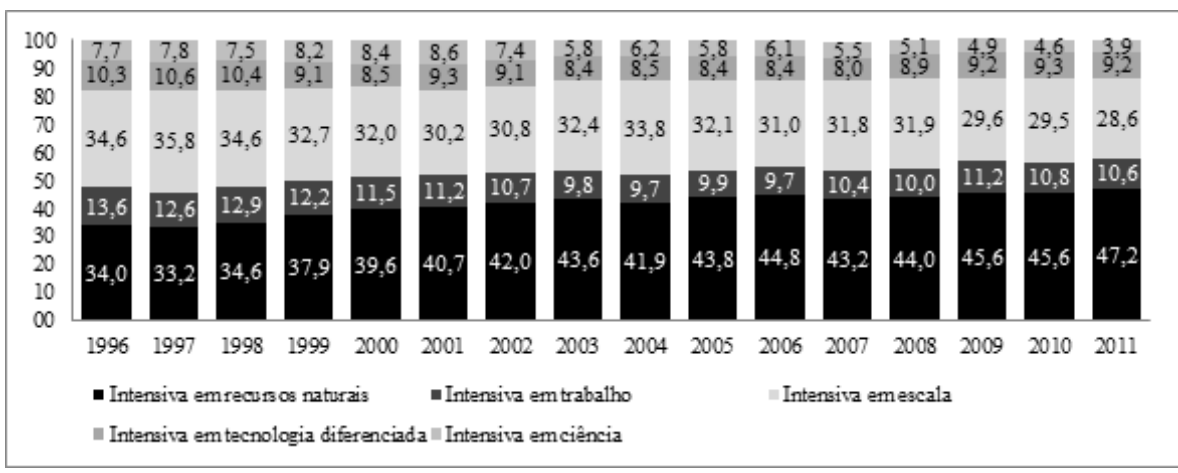

Fonte: Elaboração própria a partir de IBGE-PIA (2013).

Nota-se no Gráfico 2 que o grupo de atividades intensivas em recursos naturais ampliou significativamente sua participação no VTI do país, haja vista que, em 1996, a participação do grupo era de 34\% e, em 2011, foi cerca de 47\% do VTI. Nesse grupo, destacam-se as atividades relacionadas à fabricação de coque, de produtos derivados do petróleo (refino) e de biocombustíveis, cuja participação dobrou entre o início e o fim do período, passando de 7 para 14\%, e do ramo relacionado à extração de minerais metálicos, no qual se observa um salto de cerca de 1,5 para 7,6\% entre 1996

$4 \quad$ Além de outros citados neste trabalho, destaca-se aqui, por exemplo, Reinert (1999), que observa que um aspecto comum a todas as estratégias bem-sucedidas de catching-up adotadas pelos países atualmente industrializados está no adiamento da adoção de práticas de livre-comércio, até que essas nações tenham desenvolvido vantagens comparativas nas atividades econômicas "certas" (aquelas baseadas em capacitações e conhecimento, não em recursos naturais).

5 A agregação foi realizada com base nos dados da Pesquisa Industrial Anual (PIA), realizada pelo Instituto Brasileiro de Geografia e Estatística (IBGE). Ressalta-se que há no período analisado um corte metodológico nos dados. A partir de 2008, a PIA deixou de ser apresentada de acordo com a Classificação Nacional de Atividades Econômicas 1.0 (CNAE 1.0) e passou a ser divulgada com a nova CNAE 2.0. Com isso, utilizaram-se as desagregações de 3 dígitos da CNAE 2.0 e 1.0, de modo a possibilitar um agrupamento harmônico das atividades. O Apêndice A detalha essa classificação. 
e 2011. Além de representar o progresso tecnológico nesses ramos produtivos e a abundante disponibilidade de matéria-prima básica como principal fator de competitividade, o crescimento parece estar intimamente ligado aos picos de preços das commodities energéticas e minerais observados na última década no mercado internacional, além, obviamente, da forte demanda dos países asiáticos por esses produtos.

Por outro lado, verifica-se que o setor intensivo em escala, que era em 1996 e 1997 o setor de maior contribuição no VTI do país, representando cerca de 36\% deste, teve sua participação reduzida gradativamente nos anos subsequentes, registrando, em 2011, valor inferior a 30\%. Nesse setor, embora diversos ramos tenham apresentado ligeiras reduções de participação, destaca-se a importância do segmento produtor de veículos automotores, reboques e carrocerias para a indústria brasileira, o qual, inclusive, ampliou seu peso relativo entre 1996 e 2011, passando de 8\% para 10\%.

Já os setores intensivos em trabalho e tecnologia diferenciada, apesar da leve queda observada entre o início e o fim do período, mantiveram, em média, o mesmo patamar de participação no valor da produção industrial. No primeiro grupo, a principal mudança estrutural parece ter ocorrido na fabricação de produtos têxteis, que tem perdido espaço no VTI ao longo do período. Em 1996, por exemplo, a parcela relativa a essa atividade era em torno de 3,3\% e, a partir de meados do ano 2000, passou a declinar consideravelmente, registrando, em 2011, menos de 1,6\%. Esse processo pode ser reflexo da ampliação da concorrência com os manufaturados têxteis asiáticos, os quais têm uma grande vantagem competitiva devido à abundância do fator trabalho. No grupo de indústrias intensivas em tecnologia diferenciada, o principal segmento é o de fabricação de máquinas e equipamentos, cuja participação no VTI se situou entre $5 \%$ e $6 \%$ no período.

Por fim, o setor intensivo em ciência, embora tenha assinalado 8,6\% do VTI em 2001 , seguiu, a partir daí, tendência de queda até 2011 , quando representou apenas 3,9\%. Nessa esfera, o destaque é a fabricação de material eletrônico e de aparelhos e equipamentos de comunicações e o segmento de produtos farmoquímicos e farmacêuticos, que representavam cerca de 3,5\% do VTI no início do período, mas tiveram suas participações reduzidas para $2 \%$ e 1,4\%, respectivamente.

Em síntese, a análise da estrutura do valor da transformação industrial, segundo parâmetros tecnológicos, evidencia mudanças especialmente nos extremos dos setores industriais. Em uma ponta, a indústria intensiva em recursos naturais vem ampliando significativamente sua importância no valor da transformação industrial, superando o peso relativo do setor intensivo em escala e ficando bem próxima da metade do total da indústria. Na outra ponta, a indústria intensiva em ciência segue perdendo espaço. 


\section{Reflexos da Estrutura Produtiva no Comércio Exterior}

Após verificar o perfil da estrutura produtiva, pretende-se, nesta seção, analisar a estrutura de comércio do Brasil com o resto do mundo e verificar se houve mudanças no padrão de especialização internacional da indústria brasileira.

Antes de abordar a questão da estrutura de comércio, é interessante verificar a relação entre o desempenho da produção industrial e o comércio varejista. Conforme o Gráfico 3, a partir de meados de 2006 inicia-se um processo de descolamento dos índices quantum desses setores. Ademais, desde 2010, o gap entre os dois tem se tornado cada vez maior, devido à estagnação da produção industrial.

Gráfico 3 - Produção industrial e comércio varejista - Brasil: jan/2003-dez/2012 (quantum)

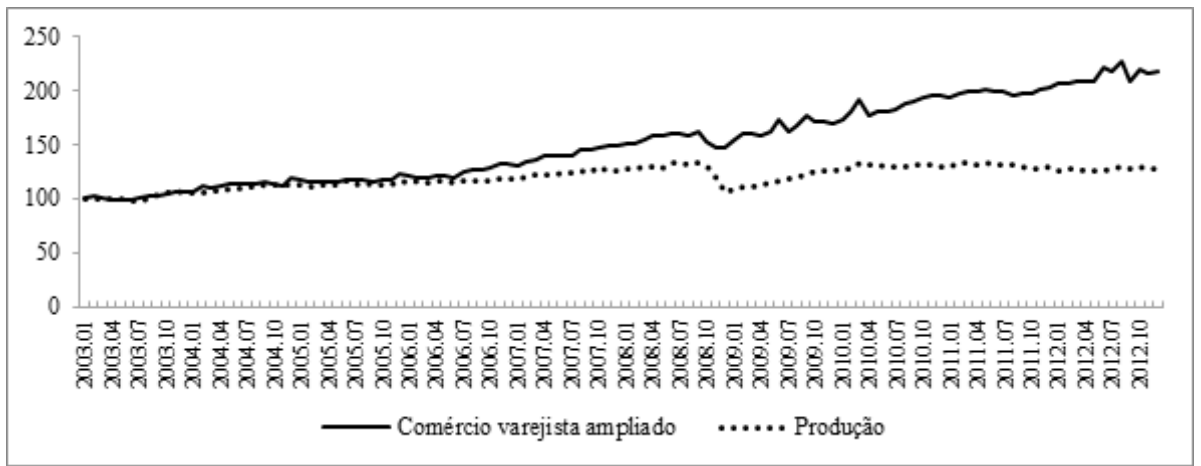

Fonte: Elaboração própria a partir de IBGE-PIM e PMC (2013).

Nota: ${ }^{1}$ Índice quantum trimestral médio. Base jan./2003.

Esse processo pode, entre outros fatores, encontrar explicação no aumento do coeficiente de penetração das importações, que passou de cerca de $15 \%$ em 2006 para aproximadamente $22 \%$ em 2012, conforme o Gráfico 4. Ressalte-se, que, desde 2003, anos seguidos de apreciação cambial podem ter levado as empresas domésticas a um comportamento defensivo, substituindo bens de capital e insumos por produtos importados. 


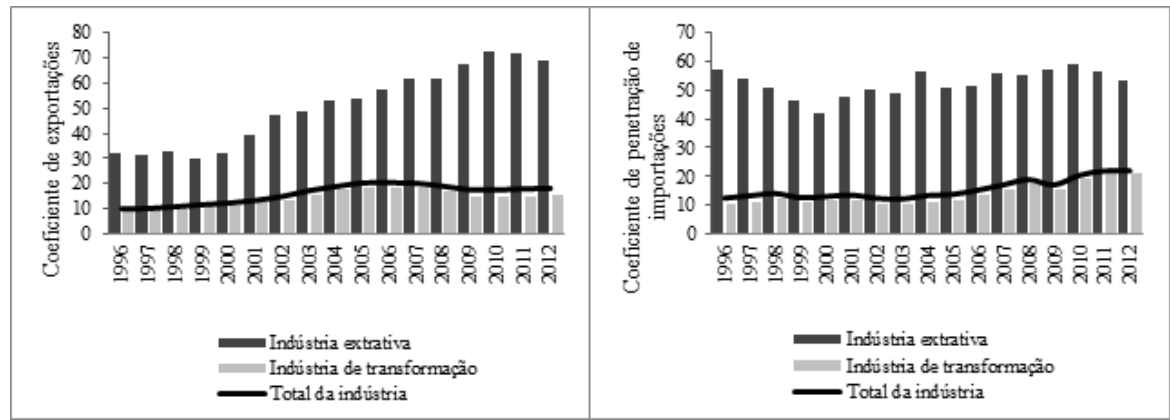

Fonte: Elaboração própria a partir de Fundação Centro de Estudos do Comércio Exterior (2013). Nota: ${ }^{1}$ Coeficientes de abertura comercial a preços constantes de 2007.

O coeficiente de exportações da indústria, por sua vez, segue trajetória oposta, passando de $20 \%$ em 2006 para 18\% em 2012. Nesse particular, coincidentemente ou não, ao longo da trajetória de depreciação cambial - 1996 a 2001 -, o coeficiente de exportações seguiu trajetória ascendente, enquanto o de importações manteve-se no mesmo patamar. Por outro lado, no período de apreciação cambial - 2004 a 2011 -, os coeficientes de exportação declinaram, enquanto os coeficientes de importação se elevaram aceleradamente.

Esses dados parecem ainda evidenciar, de um lado, uma perda de competitividade da indústria de transformação no comércio exterior, e, de outro, um ganho de competitividade da indústria extrativa, além de revelar um elevado grau de abertura. Após um crescimento entre 1996 (9,2\%) e 2005 (18,7\%), o coeficiente de exportações da indústria de transformação passou a declinar, estacionando no patamar de 15\% em 2011 e 2012. Os coeficientes de penetração de importações no setor, por sua vez, passaram de $10 \%$ em 1996 para 21\% em 2012, e superam, desde 2008, o coeficiente de exportações. No caso da indústria extrativa, seus coeficientes de exportação cresceram consideravelmente no período, passando de $32 \%$ para cerca de $70 \%$, enquanto o coeficiente de importações manteve-se na casa dos $50 \%$.

Partindo para uma análise mais específica, a Tabela 1 mostra os saldos comerciais ${ }^{6}$ da indústria brasileira segundo os parâmetros tecnológicos abordados na seção anterior, incluindo os produtos primários, no período 1996-2012.

6 Os combustíveis foram excluídos da conta, haja vista o aumento recente da importação de combustíveis, pressionado especialmente pela expansão do consumo de gasolina nos últimos anos, de forma que as distribuidoras nacionais, entre elas a Petrobras, tiveram que importar o produto para suprir a demanda interna. 
Tabela 1 - Saldo setorial do comércio internacional - Brasil: 1996-2012 (US\$ milhões)

\begin{tabular}{l|c|c|c|c|c|c}
\hline $\mathbf{A n o}$ & $\begin{array}{c}\text { Produtos } \\
\text { primários }\end{array}$ & $\begin{array}{c}\text { Intensiva } \\
\text { em } \\
\text { recursos } \\
\text { naturais }\end{array}$ & $\begin{array}{c}\text { Intensiva } \\
\text { em } \\
\text { trabalho }\end{array}$ & $\begin{array}{c}\text { Intensiva } \\
\text { em } \\
\text { escala }\end{array}$ & $\begin{array}{c}\text { Tecnologia } \\
\text { diferenciada }\end{array}$ & $\begin{array}{c}\text { Intensiva } \\
\text { em } \\
\text { ciência }\end{array}$ \\
\hline $\mathbf{1 9 9 6}$ & 3168.7 & 7328.0 & 984.1 & 1685.2 & -5123.4 & -7740.7 \\
$\mathbf{1 9 9 7}$ & 6396.0 & 6700.5 & 837.2 & 1122.0 & -7354.3 & -8863.1 \\
$\mathbf{1 9 9 8}$ & 6105.4 & 5614.9 & 868.7 & 644.0 & -7773.2 & -7890.0 \\
$\mathbf{1 9 9 9}$ & 5998.5 & 7138.0 & 1560.0 & 1810.2 & -6815.5 & -6729.6 \\
$\mathbf{2 0 0 0}$ & 6311.3 & 6402.0 & 2083.9 & 2799.0 & -5821.5 & -6157.2 \\
$\mathbf{2 0 0 1}$ & 7612.8 & 8196.2 & 2442.1 & 1866.2 & -7522.0 & -5426.4 \\
$\mathbf{2 0 0 2}$ & 7986.0 & 10312.5 & 2716.9 & 4340.9 & -5367.2 & -3760.0 \\
$\mathbf{2 0 0 3}$ & 10047.7 & 13586.0 & 3721.9 & 7467.1 & -2911.6 & -4553.1 \\
$\mathbf{2 0 0 4}$ & 14416.6 & 16933.9 & 4349.9 & 10674.3 & -591.3 & -6335.6 \\
$\mathbf{2 0 0 5}$ & 18010.2 & 20697.6 & 4242.1 & 14594.7 & -1311.5 & -7072.5 \\
$\mathbf{2 0 0 6}$ & 20198.3 & 24588.7 & 3753.7 & 14088.6 & -2152.5 & -10014.4 \\
$\mathbf{2 0 0 7}$ & 25585.0 & 24906.5 & 2612.4 & 11582.2 & -5916.2 & -12635.8 \\
$\mathbf{2 0 0 8}$ & 36338.1 & 23483.0 & 149.6 & 6737.0 & -12210.4 & -18667.9 \\
$\mathbf{2 0 0 9}$ & 34334.4 & 26129.5 & -1427.2 & -1512.1 & -13983.7 & -15813.9 \\
$\mathbf{2 0 1 0}$ & 51691.8 & 30446.6 & -3440.6 & -7803.1 & -20512.7 & -23808.2 \\
$\mathbf{2 0 1 1}$ & 74553.5 & 31009.9 & -5885.3 & -9186.3 & -22856.2 & -27648.9 \\
$\mathbf{2 0 1 2}$ & 66763.2 & 30091.7 & -7265.2 & -10546.9 & -22971.8 & -28016.0 \\
\hline
\end{tabular}

Fonte: Elaboração própria a partir de Fundação Centro de Estudos do Comércio Exterior (2013).

A Tabela 1 revela que, no último quadriênio, apenas os setores produtores de bens primários e da indústria intensiva em recursos naturais registraram superávits comerciais, enquanto o restante das indústrias, notadamente aquelas de maior dinamismo tecnológico, registrou déficits crescentes. O superávit comercial dos produtos primários, em particular, experimentou um forte crescimento no período, passando de cerca de US $\$ 3$ bilhões em 1996 para mais de US $\$ 65$ bilhões em 2012. Nota-se, também, que o ano de 2009 marca uma inflexão nos saldos comerciais das indústrias intensivas em trabalho e em economias de escala, que desde 1996 vinham apresentando saldos comerciais positivos.

As indústrias baseadas em tecnologia diferenciada e em ciência, por sua vez, registraram déficits comerciais recorrentes no período abordado, sendo que os saldos negativos, que vinham se reduzindo entre 1996 e 2003, foram significativamente ampliados entre 2004 e 2012. 
No que se refere à participação desses setores na pauta brasileira de exportações e importações no período 1996-2012, nota-se que, enquanto os setores industriais intensivos em recursos naturais têm mantido sua elevada participação no valor das exportações, os produtos primários ampliaram significativamente sua parcela entre 2004 e 2012, em detrimento dos outros setores. Destaca-se que os setores intensivos em ciência elevaram sucessivamente sua participação até o início dos anos 2000 e, depois, perderam espaço, retornando ao patamar inicial. No mesmo período, os setores intensivos em trabalho e em economias de escala também apresentaram uma queda significativa, enquanto o setor intensivo em tecnologia diferenciada assinalou uma redução menos acentuada, como pode ser observado no Gráfico 5.

Gráfico 5 - Composição setorial do valor das exportações - Brasil: 1996-2012 (em \%)

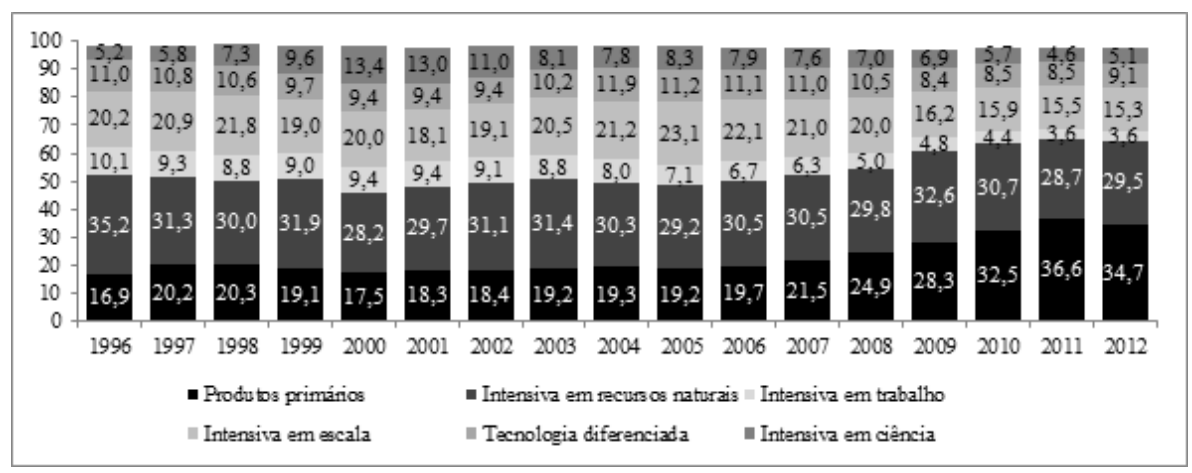

Fonte: Elaboração própria a partir de Fundação Centro de Estudos do Comércio Exterior (2013).

Pela ótica das importações, são os produtos de média-alta e alta intensidade tecnológica que têm sua participação relativa aumentada. Nos últimos anos, observa-se um comportamento simétrico, isto é, enquanto as exportações de produtos primários e de produtos industriais intensivos em recursos naturais e em trabalho têm representado aproximadamente $70 \%$ do total, os produtos industriais intensivos em economias de escala, tecnologia diferenciada e ciência têm correspondido a cerca de $70 \%$ do total importado, conforme Gráfico 6. 
Gráfico 6 - Composição setorial do valor das importações - Brasil: 1996-2012 (em \%)

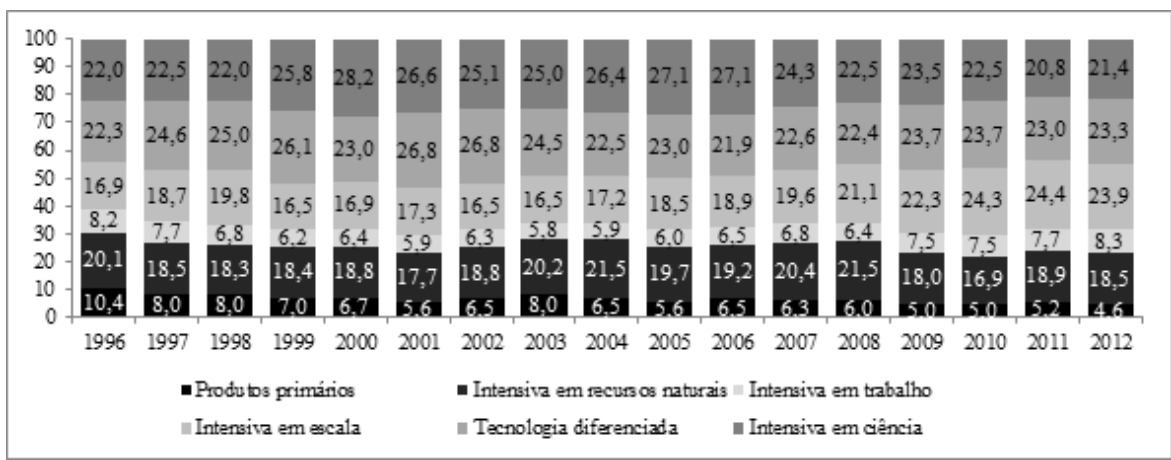

Fonte: Elaboração própria a partir de Fundação Centro de Estudos do Comércio Exterior (2013).

Em suma, os dados recentes da balança comercial brasileira não podem ser vistos com otimismo. As características estruturais das trocas do país e, consequentemente, de parte relevante da restrição externa revelam uma sistemática tendência à concentração, pelo lado das exportações, em mercados de baixa elasticidade-renda e baixo dinamismo tecnológico, enquanto, pelo lado das importações, nota-se um enrijecimento da pauta com acréscimo das importações em setores tecnologicamente mais dinâmicos.

A fim de apresentar um panorama geral da inserção externa do Brasil na esfera comercial e a competitividade desses setores no mercado internacional, a Figura 1 mostra o market share ${ }^{7}$ das exportações e importações brasileiras no total global no período de 1996-2012.

$7 \quad$ Market share $=X_{i} / X_{j} ; M_{i j} / M_{j}$. Em que: $X_{i j}=$ exportações do grupo setorial $i$ pelo país $j ; X_{j}=$ exportações mundiais do grupo setorial $i ; M_{i j}=$ importações do grupo setorial $i$ pelo país $j ; M_{\mathrm{i}}=$ importações mundiais do grupo setorial $i$. 
Figura 1 - Market share setorial das exportações e importações - Brasil: 1996-2012 (em \%)

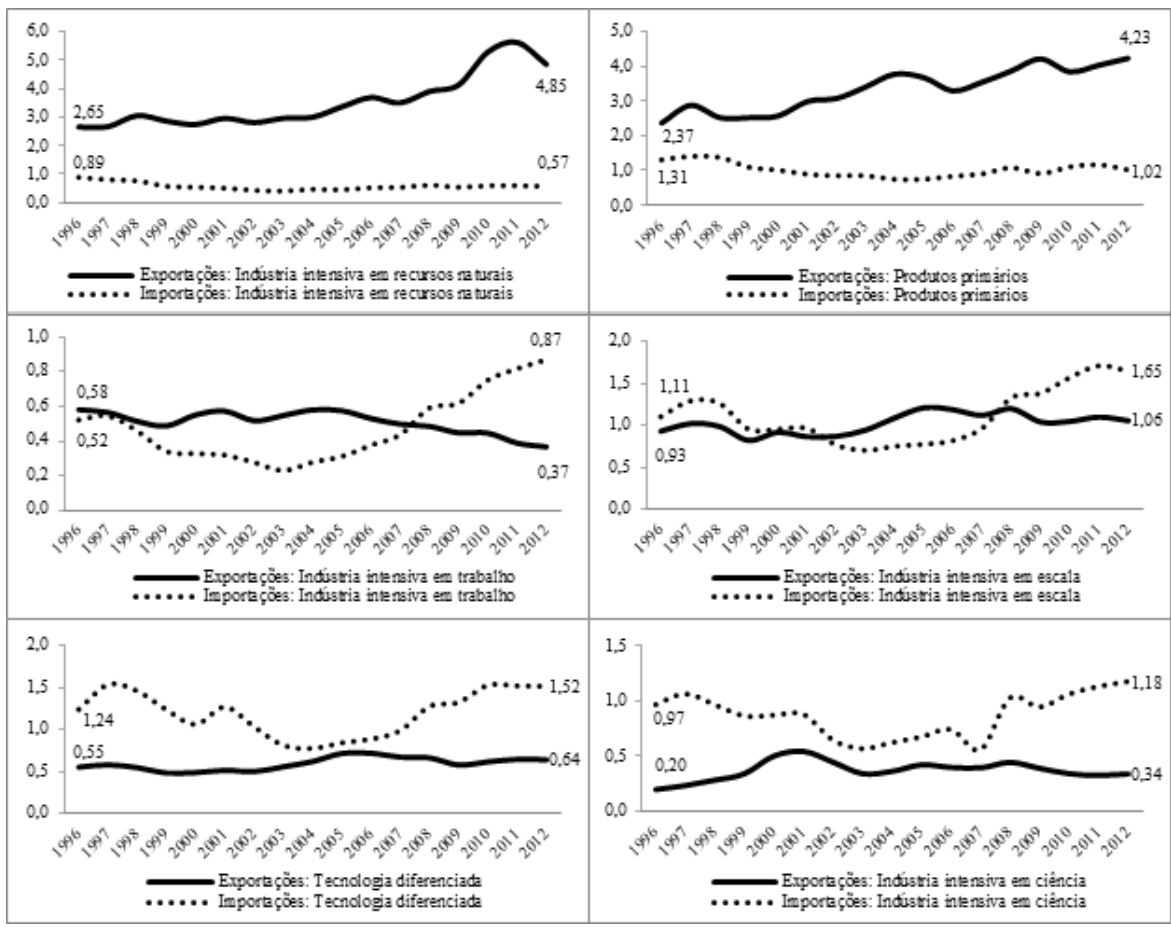

Fonte: Elaboração própria a partir de United Nations Conference on Trade and Development (2013).

Em linhas gerais, a Figura 1 evidencia que, à exceção dos setores intensivos em trabalho, as exportações de todos os setores têm ampliado suas parcelas no mercado global entre 1995-2012, com destaque para os setores de bens primários e intensivos em recursos naturais. No entanto, para os setores de maior dinamismo tecnológico, o ganho de market share das exportações tem sido inferior ao das importações, cujo avanço se mostra evidente a partir de 2004. Com efeito, como mostra a Tabela 1, os déficits nesses setores mais intensivos em tecnologia têm pressionado cada vez mais o saldo comercial do país.

Por fim, para efeito de análise de especialização e competitividade no mercado internacional, é interessante verificar a evolução de outros indicadores. Um dos mais utilizados na literatura sobre o tema é o indicador de Vantagem Comparativa Revelada (VCR), ou apenas índice de especialização, desenvolvido por Balassa (1965, p. 99-123). ${ }^{8}$ Caso o VCR seja maior que a unidade, isso significa que o país possui um market share neste setor superior à sua participação no mercado mun-

8 Vantagem Comparativa Revelada $(\mathrm{VCR})=\left(X_{\mathrm{i} j} / X_{\mathrm{j}}\right) /\left(X_{i} / X_{)}\right.$. Onde: $X_{\mathrm{ij}}=$ exportações do grupo setorial $i$ pelo país $j ; X_{i}=$ exportações mundiais do grupo setorial $i ; X_{j}=$ exportações totais realizadas pelo país $j$; $X=$ exportações mundiais totais. 
dial de todos os outros produtos. Em outros termos, significa que o país j possui vantagens comparativas no grupo setorial $i$ relativamente à economia mundial, decorrente de sua especialização no setor. Caso o índice seja menor que 1, o país não apresenta vantagens comparativas reveladas, e se igual a 1, o país possui a mesma competitividade média observada no comércio internacional.

Vale mencionar que na primeira definição de VCR, feita por Balassa (1965), adotou-se a suposição de que as diferentes dotações de fatores resultariam numa estrutura característica (padronizada) de exportações, sendo, portanto, perfeitamente compatível com as hipóteses da teoria clássica do comércio internacional. Em outras palavras, o indicador de VCR procuraria expressar, a posteriori, as vantagens relativas de custos de diferentes países a partir de suas especializações comerciais. Entretanto, ressalta-se que este indicador é somente uma variável de resultado, a qual objetiva captar no âmbito do mercado os efeitos finais do comércio internacional, sem que exista nenhuma interação obrigatória entre oferta de fatores e tais efeitos. Ao contrário, tais efeitos devem ser interpretados como resultado de assimetrias intra e intersetoriais entre os diferentes países, onde os padrões de especialização expressam, de um lado, diferenças nas assimetrias tecnológicas e vantagens relativas de custos dos países e, de outro, diferenças nas elasticidades-renda dos grupos setoriais (DOSI; PAVITT; SOETE, 1990).

Ademais, conforme Laursen (1998), esse índice apresenta a limitação estatística de que a vantagem e a desvantagem comparativa possuem dimensão assimétrica, i.e., a primeira varia de 0 a 1 , enquanto a segunda varia entre 1 e $\infty$, não respeitando a hipótese de normalidade do termo residual em qualquer análise de regressão. Essa grande variabilidade, portanto, impossibilitaria a comparação adequada entre os setores ou produtos, uma vez que naqueles em que há uma especialização virtuosa ou vantagem comparativa os valores tendem a ser superestimados, e naqueles em que há uma especialização negativa ou desvantagem comparativa os valores tendem a ser subestimados. A solução proposta pelo autor foi tornar o VCR simétrico, definindo os intervalos de referência entre -1 e + 1 com um valor médio centrado em zero. ${ }^{9}$

Outro ponto ressaltado na literatura é que o indicador VCR considera apenas as exportações no cálculo da posição competitiva de um setor de um país, sem nenhuma referência aos fluxos de importações, o que limitaria a inferência a partir dos resultados. Nesse contexto, o Centre D'études Prospectives et D'informations Internationales (1983) desenvolveu uma medida de vantagens comparativas baseada em saldos comerciais e não apenas em fluxos de exportações, o Índice de Contribuição ao Saldo Comercial (ICSC), também conhecido como Índice de Lafay (1990).

$9 V C R S=(V C R-1) /(V C R+1)$ onde VCRS é o VCR simétrico (normalizado). 
O ICSC utiliza-se de um recurso analítico denominado "saldo teórico", que é o saldo global de um país distribuído de maneira equiproporcional entre os setores presentes na sua balança comercial. Então, calculam-se os desvios dos saldos efetivos setoriais em relação ao "saldo teórico". Ou seja, esse indicador destaca a capacidade de um setor ser relativamente superavitário, no caso de vantagens comparativas, ou relativamente deficitário, no caso de desvantagens, e não apenas seu saldo comercial absoluto. Assim, esse indicador expressa as vantagens relativas dos países a partir de suas diferentes competitividades setoriais, de modo que um país deveria apresentar saldos comerciais positivos naqueles setores intensivos no fator que possui em abundância, ao mesmo tempo em que o processo de inovação tecnológica, enquanto elemento decisivo na diminuição relativa de custos e na obtenção de economias de escala, também determina as vantagens comparativas no comércio internacional. Desse modo, um valor ICSC maior que 1 indica que o país j possui vantagens comparativas no grupo setorial $i$, em que este contribui positivamente ao saldo comercial e, caso contrário (ICSC $<1$ ), o país possui desvantagens comparativas no setor, com este contribuindo negativamente ao saldo comercial. ${ }^{10}$ Entretanto, assim como o VCR, o ICSC continua sendo um indicador de resultado, expressando as vantagens relativas apenas a posteriori.

O interessante é que enquanto o VCR expressa o grau de vantagem competitiva (especialização) das exportações de um setor específico, o ICSC expressa se o país em questão possui vantagem competitiva sobre seus concorrentes no comércio desse setor específico. Um VCR positivo indica que o país é especializado nas exportações do setor em questão, mas não significa que este setor contribui positivamente para sua balança comercial. Por exemplo, caso o VCR seja positivo e o ICSC negativo, isso significa que o grau de especialização desse setor nacional não é suficiente para que este seja competitivo no mercado mundial, e sua contribuição em termos comerciais é negativa ao país. Nesse sentido, a observação conjunta desses indicadores (Figura 2) permite avaliar a real dimensão da competividade comercial de um país ou setor, já que uma inserção externa virtuosa pressupõe que, além de o país exportar em setores dinâmicos do mercado internacional, suas exportações contribuam positivamente para o saldo comercial.

\footnotetext{
$10 \operatorname{ICSC} C_{i j}=\frac{100}{\frac{X_{j}+M_{j}}{2}} \times\left[\left(X_{i j}-M_{i j}\right) \times\left\{\left(X_{j}-M_{j}\right) \times\left(\frac{X_{i j}+M_{i j}}{X_{j}+M_{j}}\right)\right\}\right]$, onde $X_{j}$ e $M_{j}$ são as exportações e importações totais do país j, e $X_{i j}$ e $M_{i j}$ as exportações e importações do setor $i$ do país $j$.
} 
Figura 2 - VCR, VCRS e ICSC, por grupos setoriais - Brasil: 1996-2012

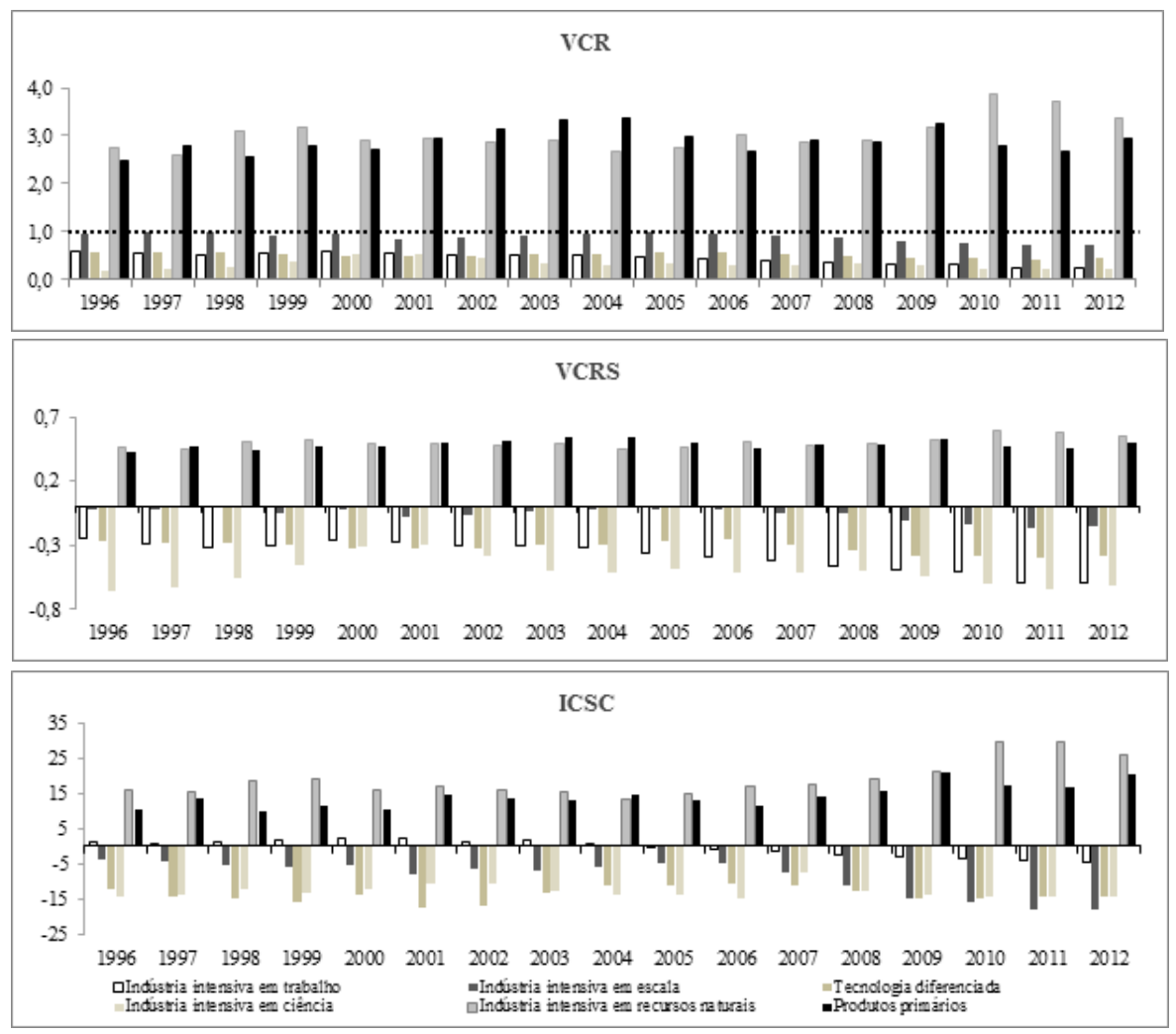

Fonte: Elaboração própria a partir de United Nations Conference on Trade and Development (2013).

Conforme a Figura 2, as exportações brasileiras apresentaram vantagens comparativas reveladas nos setores intensivos em recursos naturais e de produtos primários. Nesses setores, os indicadores VCR, VCRS e ICSC mostraram-se bastante elevados ao longo de todo o período. É interessante notar que a indústria intensiva em escala apresentou em boa parte do período uma competitividade equivalente à média do comércio internacional (VCR próximo de 1 e VCRS próximo de 0), mas desde 2007 vem se distanciando desse patamar, contribuindo crescentemente de forma negativa ao saldo comercial, quadro que se agravou a partir de 2009, evidenciando a perda de competitividade do setor no pós-crise global. Já os setores intensivos em trabalho, tecnologia diferenciada e em ciência apresentaram índices VCR e VCRS historicamente baixos, e em declínio significativo a partir de meados dos anos 2000. No caso das exportações do setor intensivo em trabalho, embora estas não apresentassem vantagens comparativas no período, nota-se que o setor contribuía positivamente ao saldo comercial até 2004, e a partir daí inicia-se uma tendência de contribuição negativa. 
Assim, embora a produção de commodities primárias e de bens intensivos em recursos naturais seja uma vantagem do Brasil no período de recessão dos países desenvolvidos - que comprimiu a demanda por manufaturados, mas em que se manteve a demanda por produtos básicos por parte dos mercados asiáticos - os setores tecnologicamente mais dinâmicos têm apresentado vantagens comparativas reveladas bastante baixas e em declínio. Nesse caso particular, o Brasil parece caminhar na contramão das experiências internacionais bem-sucedidas, isto é, de ganhos de competitividade no mercado externo ancorados cada vez mais na capacidade tecnológica e na inovação do que nos recursos naturais e fatores básicos de produção. Afinal, como observado na publicação do Instituto de Pesquisa Econômica Aplicada (2009), se, na década de 1990, o objetivo principal era gerar saldos positivos na balança comercial e, deste modo, tanto fazia se as exportações eram de banana ou de aviões, atualmente, galgar degraus de desenvolvimento tecnológico é essencial para a estratégia de desenvolvimento de qualquer país e, como a experiência demonstra, nenhuma nação da dimensão do Brasil avançou sem aperfeiçoar a indústria.

À luz do exposto anteriormente, torna-se claro que a especialização nos segmentos de menor valor agregado e que possuem uma baixa elasticidade-renda de suas demandas é preocupante para o comércio exterior do país. Mesmo que não se possa afirmar categoricamente que haja um processo de "especialização regressiva" da indústria brasileira, não se pode deixar de considerar que a atual dinâmica comercial contribui para a constituição de um quadro no qual a capacidade de geração de divisas por meio do comércio exterior seja altamente dependente da trajetória dos preços de commodities primárias e produtos intensivos em recursos naturais. A maior dependência em relação a esses produtos, cujos preços e volume exportado são mais sensíveis à conjuntura internacional, implicam uma elevação da vulnerabilidade externa estrutural do país na esfera comercial, além do já referido entrave ao crescimento econômico sustentado no longo prazo.

\section{Estrutura Produtiva e Taxa de Câmbio}

Esta seção busca, num primeiro momento, relacionar a evolução da indústria de transformação brasileira ao comportamento da taxa de câmbio real nas últimas décadas para, em seguida, analisar os efeitos da taxa de câmbio sobre o valor da transformação industrial. Esses efeitos foram estimados pela metodologia de dados em painéis, utilizando-se os modelos de efeitos fixos e de dados em painéis dinâmicos. 


\subsection{Taxa de Câmbio Efetiva Real e Participação da Indústria de Transformação no PIB}

O Gráfico 7 mostra as evoluções conjuntas da participação da indústria de transformação no produto interno bruto da economia brasileira e da taxa de câmbio efetiva real em números índices.

Gráfico 7 - Taxa de câmbio efetiva real e participação

da indústria de transformação no PIB

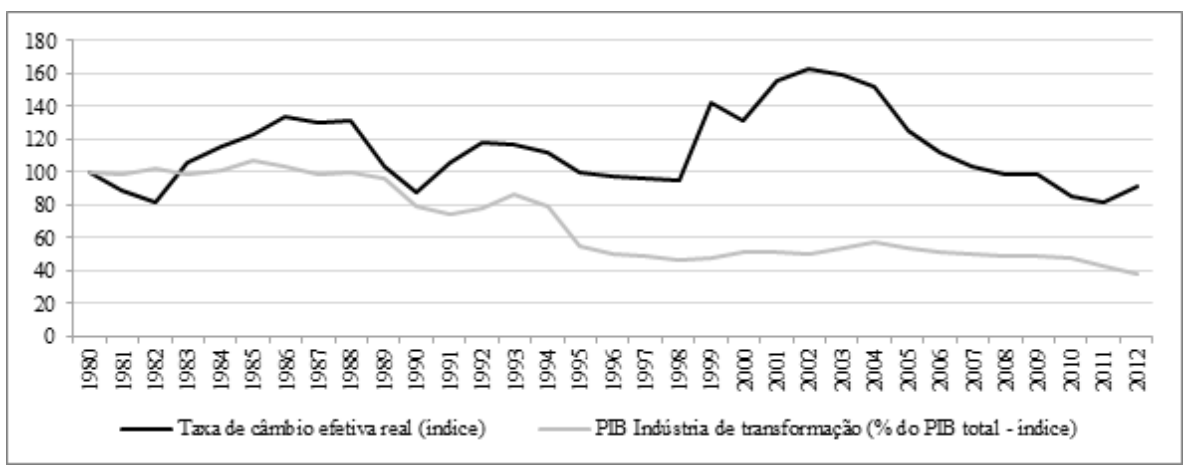

Fonte: Elaboração própria a partir de Instituto de Pesquisa Econômica Aplicada (2013).

Pelo gráfico, é possível observar que a apreciação cambial está associada a uma perda expressiva de participação da indústria no total da economia, que, entre 1980 e 2012, além da existência de dois diferentes padrões de evolução das séries taxa de câmbio efetiva real e PIB industrial. Essa perda de participação da indústria no total da economia aponta para a ocorrência de um processo de desindustrialização relativa da economia brasileira pós-abertura e pós-Real. A queda relativa do valor adicionado industrial se inicia no período pré-abertura, quando a perda de participação da indústria no PIB não pode ser atribuída ao processo normal de desenvolvimento econômico, segundo o qual, no longo prazo, o setor de serviços avança, com consequente redução da participação relativa do setor industrial e agrícola.

Outra constatação interessante é que, até a metade da década de 1990, aproximadamente, a participação relativa da indústria de transformação no PIB e a taxa de câmbio efetiva real compartilhavam uma tendência comum e positiva, de forma que aumentos na taxa de câmbio eram seguidos por maior participação do setor industrial na economia. A partir daí, porém, essas variáveis se desconectam, exibindo um padrão muito diferente de evolução em que a participação do valor adicionado da indústria no PIB se mostra pouco sensível ao novo regime cambial.

A interpretação do resultado da primeira fase pode partir do fato de que a indústria, nesse período, era composta por ramos que se constituíram sob a ló- 
gica e as incitações econômicas do modelo de industrialização por substituição de importações (MISI). Na vigência deste modelo, uma taxa de câmbio competitiva ou suficientemente depreciada era uma das macrovariáveis básicas para a manutenção de um ambiente macroeconômico favorável aos investimentos industriais. Mas, na passagem para o segundo período, a nova forma de inserção internacional do Brasil foi marcada por um processo acelerado de liberalização comercial e financeira, conjugado com uma forte apreciação da taxa de câmbio real, notadamente a partir de 2003.

Esse novo ambiente macroeconômico pós-abertura foi determinante para a retração ou o fechamento de diversas unidades produtivas industriais que se viram rapidamente expostas à concorrência internacional, sem o intercurso de uma política de desenvolvimento industrial consistente e adequada às necessidades do crescimento e do desenvolvimento econômico nacional. A hipótese sustentada por este estudo é a de que o regime de câmbio apreciado foi prejudicial aos setores e ramos tecnologicamente mais sofisticados, favorecendo os ramos mais tradicionais e aqueles ligados às atividades primárias. Esse regime mudou o perfil da estrutura produtiva brasileira, provocando um processo de desindustrialização relativa da economia.

Nesse caso, a indústria perdeu sua participação econômica antes mesmo de a economia ter alcançado seus estágios mais avançados de desenvolvimento. Essa desindustrialização tem como contrapartida uma expansão igualmente precoce do setor serviços ("inchaço do terciário"), conduzindo, inclusive, à precarização do trabalho e a níveis mais elevados de informalidade, sendo, portanto, um fator de bloqueio do processo de desenvolvimento econômico e social. Além disso, essa definição de desindustrialização não pode se basear apenas em indicadores de níveis de emprego, já que as atuais bases técnicas produtivas são intensivas em capital, características que conduziriam a uma queda do pessoal ocupado, podendo sinalizar, equivocadamente, para uma perda de participação da indústria no PIB.

Destaque-se que os ramos remanescentes do processo de desindustrialização da economia brasileira pós-liberalização são precisamente aqueles cuja performance é pouco afetada pelo atual regime de câmbio flutuante com forte tendência à apreciação. Apesar do discurso corrente acerca das características supostas quase sempre positivas de uma economia baseada em serviços, consagrando o uso de expressões como "economia do conhecimento", "economia pós-industrial" e "nova economia", a experiência histórica mostra que a indústria ainda é base do desenvolvimento das nações. Mesmo que nas atuais economias os serviços tenham alcançado posições qualitativa e quantitativamente proeminentes, a indústria continua sendo a principal fornecedora dos insumos fundamentais às atividades terciárias. O deslocamento do emprego industrial pelo emprego terciário não implica necessariamente perda de importância econômica do setor secundário, 
visto que a geração de valor nos serviços permanece substancialmente dependente da materialização de conceitos, de inovações tecnológicas e das infraestruturas provenientes de processos produtivos industriais. Reforçando a tendência de subavaliação da relevância da indústria pode-se acrescentar o fato de que inúmeras atividades que outrora eram consideradas tipicamente industriais têm sido reclassificadas e introduzidas no rol dos serviços, tendo-se em vista os benefícios fiscais e organizacionais dos processos de terceirização.

\subsection{Uma Investigação Empírica sobre os Efeitos da Taxa de Câmbio na Indústria}

Para investigar empiricamente os efeitos da taxa de câmbio sobre o valor da transformação industrial, utilizar-se-á o seguinte modelo: ${ }^{11}$

$$
V T I_{i t}=\alpha_{i t}+\beta 1 R E R_{i t}+\beta 2 A_{i t-1}+\beta 3 R E R_{i t} * A_{i t}+\beta 4 Y^{b r}{ }_{i t}+\beta 5 Y^{w}{ }_{i t}+\varepsilon_{i t}
$$

Em que VTI e A são, respectivamente, o valor da transformação industrial e o grau de abertura ${ }^{12}$ calculado para os setores da indústria segundo a intensidade dos fatores. RER é a taxa de câmbio efetiva real coletada no site do Ipeadata, Ybr é o PIB brasileiro e $\mathrm{Y}^{\mathrm{w}}$ é o PIB mundial, ambos em valores constantes e em dólares americanos extraídos do Fundo Monetário Internacional. ${ }^{13}$

Os dados se referem aos anos de 1996 até 2011 para os diferentes setores da indústria, classificados em cinco grandes grupos por intensidade dos fatores, sendo eles produtos intensivos em recursos naturais, intensivos em trabalho, intensivos em escala, produtos diferenciados e intensivos em ciências. Isso forma um painel com 16 anos e cinco setores.

Os resultados foram estimados pela metodologia de dados em painéis, utilizando-se os modelos de efeitos fixos e de dados em painéis dinâmicos. O objetivo de se empregar a metodologia de painéis dinâmicos é contornar o viés de endogeneidade existente no modelo, por exemplo, pelo fato de que o crescimento do PIB brasileiro tente a aumentar o valor da transformação industrial e, ao mesmo tempo, o crescimento do valor da transformação industrial também tende a aumentar o PIB brasileiro. Para solucionar esses problemas, considera-se a abordagem para modelos dinâmicos, baseada no método de momentos generalizados (GMM), proposta por

\footnotetext{
11 Este é uma adaptação do modelo estimado por Ribeiro e Pereira (2006), que investigaram o efeito da taxa de câmbio e da abertura econômica sobre a criação e destruição de emprego nas indústrias do Rio Grande do Sul.

12 O grau de abertura é aproximado pelo valor da corrente de comércio de determinado setor dividido pelo seu PIB. Os dados de comércio foram extraídos da Funcex, e o PIB setorial é o VTI disponibilizado pelo IBGE.

13 Fundo Monetário Internacional, World Economic Outlook database (2013).
} 
Arellano e Bond (1991). ${ }^{14}$ que é consistente quando aplicada a modelos dinâmicos. Os resultados para efeitos fixos estão sintetizados na Tabela 2 e o modelo dinâmico na Tabela 3.

Tabela 2 - Modelo efeitos fixos

\begin{tabular}{|c|c|c|c|c|c|c|}
\hline d.lnvti & Coef. & Desv. Pad. & $\mathbf{t}$ & $P>|t|$ & \multicolumn{2}{|c|}{ [95\% Conf. Interval] } \\
\hline RER*A & -1.552853 & 0.0859074 & -18.08 & 0.000 & -1.724693 & -1.381013 \\
\hline RER & 1.667173 & 0.2616605 & 6.37 & 0.000 & 1.143774 & 2.190572 \\
\hline$Y^{b r}$ & 0.3830068 & 0.2022533 & 1.89 & 0.063 & -0.02156 & 0.7875736 \\
\hline $\mathrm{Y}^{\mathrm{w}}$ & 1.502299 & 0.3886951 & 3.86 & 0.000 & 0.7247926 & 2.279804 \\
\hline A & 0.065307 & 0.0893073 & 0.73 & 0.467 & -0.1133343 & 0.2439483 \\
\hline Const. & -.0383442 & 0.0229088 & -1.67 & 0.099 & -0.0841685 & 0.0074802 \\
\hline \multicolumn{7}{|c|}{$\begin{array}{l}\text { Teste F }(5,60) \\
\text { Prob > F }\end{array}$} \\
\hline
\end{tabular}

Fonte: Elaboração própria com base nos dados da pesquisa.

Nota: Todas as variáveis em logaritmo natural e em primeira diferença.

Tabela 3 - Modelo painel dinâmico

\begin{tabular}{c|c|c|c|c|cc}
\hline d.lnvti & Coef. & Desv. Pad. & $\mathbf{t}$ & $\mathbf{P}>|\mathbf{t}|$ & \multicolumn{2}{|c}{ [95\% Conf. Interval] } \\
\hline $\mathrm{VTI}_{1}$ & -0.1224605 & 0.0807416 & -1.52 & 0.129 & -0.280711 & 0.0357901 \\
$\mathrm{RER}^{*} \mathrm{~A}$ & -1.544023 & 0.0795943 & -19.40 & 0.000 & -1.700025 & -1.388021 \\
$\mathrm{RER}$ & 1.725493 & 0.2443662 & 7.06 & 0.000 & 1.246545 & 2.204442 \\
$\mathrm{Y}^{\mathrm{br}}$ & 0.4606004 & 0.1931287 & 2.38 & 0.017 & 0.0820751 & 0.8391257 \\
$\mathrm{Y}^{\mathrm{w}}$ & 1.392779 & 0.3661783 & 3.80 & 0.000 & 0.6750828 & 2.110476 \\
$\mathrm{~A}$ & -0.1234476 & 0.1512994 & -0.82 & 0.415 & -0.4199889 & 0.1730937 \\
Const. & -0.0288101 & 0.022145 & -1.30 & 0.193 & -0.0722136 & 0.0145934 \\
\hline \multicolumn{7}{|c|}{ Sargan chi2(54) $=3.35909$} \\
\hline
\end{tabular}

Fonte: Elaboração própria com base nos dados da pesquisa.

Nota: Todas as variáveis em logaritmo natural e em primeira diferença.

Quanto aos efeitos do grau de abertura sobre a produção industrial, destaca-se que este pode, por um lado, estimular as importações, levando a uma queda na produção doméstica, e, por outro, estimular as exportações, induzindo a um crescimento desta variável. Assim, o impacto da abertura sobre o valor da transfor-

14 Esta abordagem geral tem sido desenvolvida em vários estágios na literatura, ver, por exemplo, Ahn e Schmidt (1995), Arellano e Bover (1995), Blundell e Bond (1998). 
mação industrial dos setores depende do seu efeito líquido sobre a diferença entre importações e exportações de produtos manufaturados.

Nos modelos estimados por efeitos fixos e painel dinâmico, essa variável não se mostrou significativa de forma direta. No entanto, para os efeitos indiretos da taxa de câmbio via interação com o grau de abertura dos setores, o sinal é negativo e significante, o que pode evidenciar que, quando há uma depreciação na taxa de câmbio, os setores mais abertos expandem menos a sua produção e, na ocorrência de uma apreciação, os setores com maior grau de abertura contraem menos o seu produto. ${ }^{15}$

O setor intensivo em recursos naturais é um dos setores com maior grau de abertura e representa cerca de $40 \%$ da indústria, o que pode evidenciar resultado análogo às interpretações extraídas do Gráfico 7, quais sejam, de que os ramos remanescentes da indústria brasileira pós-liberalização parecem ser pouco afetados pelo atual regime de câmbio flutuante com forte tendência à apreciação, haja vista que diferentes trajetórias da taxa de câmbio são compatíveis com uma mesma tendência do valor da transformação industrial. Neste setor de recursos naturais as vantagens de custo são tão declaradas que mudanças para baixo ou para cima na taxa de câmbio não são determinantes para a competitividade das exportações deste setor.

O efeito direto do câmbio foi significativo, e seu impacto mostra que um aumento na taxa de câmbio aumenta o valor da transformação industrial, evidenciando que a taxa de câmbio relativamente desvalorizada torna a indústria de transformação mais competitiva e estimula a sua produção.

Os efeitos do crescimento da economia doméstica e do resto do mundo também se mostraram positivos e estatisticamente significantes para explicarem o valor da produção industrial.

Os resultados das estimativas confirmam a importância do nível da taxa de câmbio para estimular a indústria, assim, políticas de taxas de câmbio adequadas são uma condição necessária para que os desafios impostos pela concorrência internacional possam se converter em fatores propulsores do desenvolvimento das nações. A mera adesão a um ambiente externo de alta concorrência pode acarretar perdas em setores e ramos importantes da indústria nacional, de forma que políticas proativas de desenvolvimento industrial, como a desvalorização da taxa de câmbio, apresentam-se como um recurso para o enfrentamento da concorrência externa e para a construção de vantagens competitivas dinâmicas.

15 Destaque-se que este efeito pode também estar mostrando que as respostas dos diferentes setores a mudanças na taxa de câmbio são heterogêneas e que uma análise desagregada evidenciaria mais claramente quais os setores são impactados positivamente ou negativamente pelo nível do câmbio. 


\section{Experiências Internacionais de Utilização da Taxa de Câmbio Como lm- pulso à Indústria}

Esta seção argumenta que análises históricas e comparações internacionais dão mostras de que as mudanças nas formas de inserção internacional são decisivas na reconfiguração da indústria e, mais amplamente, do próprio ambiente econômico doméstico.

Williamson (2003) destaca que a taxa de câmbio é uma variável central em estratégias de desenvolvimento. Sua convicção baseia-se na observação do êxito das economias da Ásia Oriental - inicialmente, Hong Kong, Coreia, Cingapura e Taiwan e, em seguida, os países do sudeste asiático - em sustentar altas taxas de crescimento econômico, mediante a adoção de taxas de câmbio competitivas. A maioria destas economias passou por uma fase inicial de industrialização por substituição de importação e, em vez de manterem essa estratégia a um ponto em que fossem obrigadas a construir sofisticadas indústrias para as quais a sua dotação de fatores não estava adaptada, elas se dedicaram à exportação de produtos manufaturados simples. Ao longo do tempo, a fabricação básica expandiu-se e esses países começaram a produzir e a exportar uma gama maior de produtos manufaturados. Além disso, em virtude do rápido crescimento de suas exportações, estas economias convenceram os mercados de que eram bons destinos para os fluxos de capitais, em especial para os investimentos estrangeiros diretos.

A abordagem da taxa de câmbio como estratégia de desenvolvimento recebe respaldo de Bresser-Pereira (2008, 2010), destacando que a apreciação cambial decorrente da exportação de recursos naturais inviabiliza a produção de bens comercializáveis, com destaque para os manufaturados com maior potencial de inovação tecnológica e ganhos de produtividade. O espaço dos bens manufaturados é ocupado pelo setor de recursos naturais e bens não comercializáveis, de forma que o capital e o trabalho são deslocados daqueles setores para esses. A indústria do país volta-se para dentro, especializando-se na produção de bens não comercializáveis que apresentam maior rentabilidade por conta da apreciação cambial. Evidências empíricas podem ser encontradas em Bresser-Pereira e Marconi (2008).

Ao reforçar a defesa da abordagem da taxa de câmbio como estratégia para o desenvolvimento, Frenkel (2004) também analisa a relação entre taxas de câmbio real e emprego na Argentina, no Brasil, no Chile e no México. Explica o autor que existem diversas experiências com políticas cambiais no período posterior à liberalização financeira nesses países. Muitas delas focam, primariamente, no controle da inflação, isto é, as taxas de câmbio são utilizadas como âncoras para a estabilização, como foi o caso da Argentina e do Chile nos anos 1970, do México nos anos 1980 e 1990, e da Argentina e do Brasil nos anos 1990. Em todas essas experiências, as políticas adotadas levaram a crises econômicas. Mais recentemen- 
te, regimes de taxas de câmbio flutuantes foram adotados, embora as políticas macroeconômicas continuassem, na maioria das vezes, focando no problema da inflação em detrimento das metas reais, como crescimento e emprego, que foram excluídas do foco principal das políticas cambiais.

Ao analisar a política cambial desses países entre 1980 e 2003, Frenkel (2004) conclui que preservar a competitividade e a estabilidade da taxa de câmbio real é uma das melhores contribuições que a política macroeconômica pode dar para melhorar o desempenho macroeconômico nos países em desenvolvimento. Assim, a política cambial deve ser apresentada como um componente de um regime de política macroeconômica apto a perseguir diversos objetivos - na maioria das vezes conflitantes - em um caminho coerente, que considere o crescimento e o desenvolvimento econômico de longo prazo.

Rodrik (2004) se junta aos autores que defendem a importância da política cambial como uma estratégia de crescimento. Ele entende que, para uma pequena economia aberta, a taxa de câmbio real é definida como a relação entre o preço dos produtos comercializáveis e não comercializáveis com o exterior. $\mathrm{Na}$ prática, este preço tende a se mover simultaneamente com a taxa de câmbio nominal. Assim, uma desvalorização da moeda (apoiada por políticas adequadas), implicará aumento da lucrabilidade das atividades comercializáveis com o exterior. Essa desvalorização tem uma série de vantagens. Uma delas é o início da diversificação das atividades dos países em direção a atividades não tradicionais. Outra vantagem é que as atividades comercializáveis se deparam com a concorrência externa, enfrentando maior disciplina de mercado, o que as torna mais dinâmicas relativamente às demais. Por fim, a maneira pela qual a depreciação subsidia atividades comercializáveis é amigável ao mercado, no sentido de que não requer nenhuma espécie de micro-gestão por parte dos burocratas. Baseado nisso, o autor defende que uma política crível e sustentada de desvalorização da taxa de câmbio real constitui uma das formas mais eficazes de política industrial.

Sobre a relevância do câmbio para estimular a exportação de bens não tradicionais, Gala (2007) ressalta que uma moeda depreciada ajuda a estimular o setor de produtos não tradicionais das economias em desenvolvimento, particularmente aqueles relacionados à exportação de manufaturas. Portanto, ao estimular a produção industrial para os mercados mundiais, uma taxa de câmbio competitiva pode ajudar esses países a melhorarem seu desenvolvimento tecnológico. Além disso, por aumentar a produtividade e desenvolver uma dinâmica no setor de bens exportáveis não tradicionais, a taxa de câmbio depreciada pode elevar os salários reais, compensando o efeito negativo de uma "moeda fraca" para os trabalhadores. Por outro lado, a apreciação cambial pode aumentar o componente importado da produção industrial, ao tornar vantajoso para o país importar insumos em vez de produzi-los domesticamente. Além disso, com uma taxa de câmbio 
apreciada, apenas os preços dos produtos nos quais o país possui significativas vantagens de custos tornam-se competitivos no exterior. No caso dos países em desenvolvimento, esses produtos são representados em grande medida pelas commodities e por bens ligados a elas, o que pode implicar alterações regressivas no setor industrial de seus países.

Rodrik (2008) explica que o entendimento da relação entre taxa de câmbio real e crescimento econômico deve considerar a centralidade dos produtos comercializáveis nessa relação. Entendendo o papel desses bens em gerar crescimento econômico, é possível desenvolver políticas nessa direção. Ele sugere dois grupos de explicações para a importância dos bens comercializáveis. Um enfatiza as falhas contratuais (contractual weaknesses), e o outro destaca as falhas de mercado existentes na moderna produção industrial.

Quanto ao primeiro grupo de explicações, o autor ressalta que instituições fracas geram baixas apropriações privadas dos retornos dos investimentos, o que ocorre mediante uma variedade de mecanismos: contratos incompletos, corrupção, a falta de mecanismos de proteção à propriedade intelectual, pouca efetividade dos contratos, etc. Tais problemas reprimem os incentivos para a acumulação e para o progresso técnico. Se o setor de bens comercializáveis sofre mais severamente com esse problema que o setor de bens não comercializáveis, que é uma suposição plausível desde que o sistema de produção seja mais complexo no primeiro setor, os resultados são uma má alocação de recursos nessa área e uma distorção dinâmica traduzida em menores investimentos em relação ao que seria socialmente ótimo. Nessas condições, um aumento na taxa de câmbio pode melhorar a eficiência dos bens comercializáveis e estimular o crescimento econômico, ao tornar elegível uma maior quantidade de investimentos direcionados para tais bens.

No que se refere às falhas de mercado com as quais os países em desenvolvimento se deparam, por exemplo, as imperfeições do mercado de crédito, o prêmio salarial, ${ }^{16}$ as externalidades de coordenação, ${ }^{17}$ entre outras. Esses problemas podem interferir em todos os tipos de atividades econômicas nos países em desenvolvimento, mas seus efeitos são sentidos mais intensamente no setor de bens comercializáveis, o que implica um nível de produto e investimento subótimo nesses bens. Mais uma vez, a depreciação da taxa de câmbio pode promover a capacidade de expansão do setor e, em decorrência, ampliar o crescimento econômico. Nesse caso, a taxa de câmbio depreciada funciona como uma segunda melhor solução, uma vez que a melhor solução seria identificar as falhas de mercado e resolvê-las com políticas industriais adequadas.

16 O prêmio salarial pode ser entendido como o monitoramento, a rotatividade e outros custos que mantêm os salários acima do salário de equilibrio e o emprego abaixo do nível ideal.

17 A externalidade de coordenação consiste no fato de que a criação de novas indústrias requer investimentos coordenados a montante, a jusante e lateralmente. 
Ainda é preciso mencionar aqueles autores que exploram os efeitos de mudanças na taxa de câmbio sobre a elasticidade-renda das exportações. O ponto de partida desta análise é a literatura de crescimento com equilíbrio de balanço de pagamentos, originada pelo artigo de Thirlwall (1979). ${ }^{18}$ Seu trabalho demonstra que o balanço de pagamentos é um componente crucial na restrição ao crescimento de longo prazo para diversas economias, especialmente economias menos desenvolvidas.

Sob esse contexto teórico, Barbosa-Filho (2006) analisa o papel da taxa de câmbio em uma situação de restrição de balanço de pagamentos. Isso porque mudanças prolongadas na taxa de câmbio real podem ter impactos permanentes na estrutura da economia e, assim, determinar o crescimento e o desenvolvimento econômico de longo prazo. Ele desenvolve, inicialmente, uma discussão acerca dos modelos que analisam a importância do constrangimento de balanço de pagamentos sobre o crescimento econômico, como o do próprio Thirlwall (1979), destacando a elasticidade-renda da demanda por exportações e importações. Em tais modelos, assume-se que as elasticidades são dadas no longo prazo, no sentido de que a taxa de crescimento da economia é determinada pela taxa de crescimento mundial. ${ }^{19}$

Um dos problemas desta hipótese é que as elasticidades-renda das exportações e importações estão sujeitas a mudanças estruturais de longo prazo, isto é, a própria restrição imposta pelas condições financeiras internacionais leva a mudanças nos preços relativos e na política econômica, as quais geram mudanças nas elasticidades-renda e preço das importações e exportações. Além disso, é possível acrescentar que mudanças prolongadas nos preços relativos podem ser usadas para promover alterações estruturais na economia, o que torna a restrição de balanço de pagamentos endógena no longo prazo. Assim, em vez de um efeito adverso da restrição de balanço de pagamentos sobre o crescimento econômico, esta pode ser alterada pela política econômica, conforme ilustrado pelo sucesso de países como China e Índia (BARBOSA-FILHO, 2006).

Ao se assumir que os parâmetros das elasticidades das funções de demanda por exportações e importações podem ser alterados pela taxa de câmbio real, uma administração adequada dessa taxa pode aliviar a restrição de balanço de pagamentos, aumentando a elasticidade-renda das exportações ou diminuindo a elasticidade-renda das importações. Ao contrário, uma administração inadequada

18 Dando continuidade ao trabalho original, outros foram desenvolvidos, por exemplo, Thirlwall e Hussain (1982) elaboraram uma versão mais desenvolvida do modelo, incorporando a possibilidade de financiar os desequilibrios em transações correntes mediante a entrada de capital, ou seja, incorporando a possibilidade de existência de um desequilỉbrio inicial do saldo em transações correntes financiado por essa entrada de capital.

19 A lei de Thirlwall afirma que a taxa de crescimento com equilibrio do balanço de pagamentos depende da elasticidade-renda da demanda por importações e exportações e da taxa de crescimento do resto do mundo. 
da taxa de câmbio pode agravar essa restrição e reduzir a taxa de crescimento da economia. Assim, um dos principais resultados do artigo de Barbosa-Filho (2006) é que a taxa de câmbio pode ser um importante instrumento para estimular o crescimento e o desenvolvimento econômico mediante mudanças temporárias, mas suficientemente longas, nos preços relativos entre os bens comercializáveis e não comercializáveis com o exterior.

Nessa mesma linha, Oreiro, Nakabashi e Souza (2010) se utilizam de um modelo de comércio internacional para explicar a relação entre taxa de câmbio e elasticidade-renda das exportações. Na definição dos autores, o grau de especialização produtiva de uma economia, isto é, o número de diferentes tipos de bens produzidos, é determinado pela razão entre o salário real doméstico e o salário real pago pelo resto do mundo. Assim, quanto maior for o salário real pago na economia doméstica relativamente ao salário real pago no resto do mundo, maior será o nível de especialização produtiva do país. Além disso, quanto maior a especialização produtiva, menor será o crescimento das exportações, em virtude do crescimento da renda do resto do mundo, o que implica menor elasticidade-renda das exportações.

Os autores afirmam que a taxa real de câmbio influencia o grau de especialização produtiva da economia à medida que ela tem um impacto direto sobre o salário real. Sendo assim, a apreciação do câmbio real tende a causar um aumento do salário real, aumentando o custo de produção no país relativamente ao custo de produção no resto do mundo. Esse processo induz a migração de atividades produtivas, antes realizadas na economia doméstica, para o exterior, causando uma desindustrialização da economia doméstica e afetando a capacidade exportadora do país.

Com base nesta concepção, Oreiro, Nakabashi e Souza (2010) discutem a relação linear entre taxa de câmbio depreciada e elasticidade-renda das exportações nos países em desenvolvimento. No entender dos autores, uma taxa de câmbio depreciada pode aumentar a elasticidade-renda das exportações ao fazer com que mais produtos nacionais tornem-se competitivos no mercado externo.

A importância das taxas de câmbio desvalorizadas para estimular a elasticidade-renda das exportações e relaxar a restrição de balanço de pagamentos nos países em desenvolvimento, destacada no artigo de Barbosa-Filho (2006) e de Oreiro, Nakabashi e Souza (2010), recebe respaldo das experiências internacionais, por exemplo, dos países do leste asiático, que subsidiaram as exportações e taxaram as importações via taxas de câmbio competitivas, gerando importantes incentivos à produção de bens comercializáveis.

Em suma, as análises mencionadas anteriormente ressaltam que a manutenção da taxa de câmbio em níveis competitivos pode estimular o setor industrial e o crescimento econômico, destacando experiências bem-sucedidas de países que 
utilizaram tal estratégia em contraste a países que se devotaram à política cambial apenas para solucionar problemas inflacionários.

\section{Considerações Finais}

Neste artigo, a análise da estrutura do valor da transformação industrial segundo parâmetros tecnológicos evidenciou mudanças especialmente nos extremos dos setores industriais. Em uma ponta, a indústria intensiva em recursos naturais vem ampliando significativamente sua importância no valor da transformação industrial, superando o peso relativo do setor intensivo em escala e ficando bem próxima da metade do total da indústria. Na outra ponta, a indústria intensiva em ciência segue perdendo espaço.

Esse padrão de especialização se reflete na atual dinâmica comercial, porque a capacidade de geração de divisas por meio do comércio exterior de bens é altamente dependente da trajetória dos preços das commodities primárias e dos produtos intensivos em recursos naturais. A maior dependência em relação a esses produtos, cujos preços e volume exportado são mais sensíveis à conjuntural internacional, pode implicar uma elevação da vulnerabilidade externa estrutural do país na esfera comercial. Por outro lado, as evidências empíricas internacionais mostram que o crescimento econômico no mundo em desenvolvimento está negativamente correlacionado com a dependência contínua das exportações de bens primários e intensivos em recursos naturais, mas é positivamente correlacionado com a diversificação em direção a produtos manufaturados de média e alta tecnologia.

Quanto ao papel da taxa de câmbio neste processo, destacou-se que o regime de câmbio apreciado foi prejudicial aos setores e ramos tecnologicamente mais sofisticados, favorecendo os ramos mais tradicionais e aqueles ligados às atividades primárias. Este regime contribuiu para alterar o perfil da estrutura produtiva brasileira, provocando um processo de desindustrialização relativa da economia brasileira.

Dada a influência que a taxa de câmbio exerce sobre a estrutura produtiva, destaca-se que políticas de taxas de câmbio adequadas são uma condição necessária para que os desafios impostos pela concorrência internacional à indústria doméstica possam se converter em fatores propulsores do desenvolvimento econômico. A mera adesão a um ambiente externo de alta concorrência pode acarretar perdas em setores e ramos importantes da indústria nacional, de forma que políticas proativas de desenvolvimento industrial, como a desvalorização da taxa de câmbio, apresentam-se como um recurso para o enfrentamento da concorrência externa e para a construção de vantagens competitivas dinâmicas. 


\section{Referências}

AGUIRRE, A.; CALDERÓN, C. Real exchange rate misalignment and economic performance. Chile: Central Bank of Chile, 2005. (Working paper, n. 316).

AHN, S.; SCHMIDT, P. Efficient estimation of models for dynamic panel data. Journal of Econometrics, v. 68, n. 1, p. 5-27, 1995.

ARAÚJO, E.; BRUNO, M.; PIMENTEL, D. Regime cambial e mudança estrutural na indústria de transformação brasileira: evidências para o período (1994-2008). Revista de Economia Política, v. 32, n. 3, p. 424-444, jul./set. 2012.

ARAÚJO, R. A.; LIMA, G. T. A structural economic dynamics approach to balance-ofpayments constrained growth. Cambridge Journal of Economics, v. 31, n. 5, p. 755-774, 2007.

ARELLANO, M.; BOND, S. Some test s of specification for panel data: Monte Carlo evidence and an application to employment equations. The Review of Economic Studies, 58. p. 277297, 1991.

ARELLANO, M.; BOVER, O. Another look at the instrumental variable estimation of errorcomponents models. Journal of Econometrics, v. 68, n. 1, p. 29-51, 1995.

BALASSA, B. Trade liberalization and "revealed" comparative advantage. The Manchester School, v. 33, n. 2, p. 99-123, 1965.

BARBOSA-FILHO, N. H. Exchange rates, growth and inflation. In: ANNUAL CONFERENCE ON DEVELOPMENT AND CHANGE, 2006, Campos do Jordão. Anais... Campos do Jordão: ACDC, 2006.

BHADURI, A.; MARGLIN, S. Unemployment and the real wage: the economic basis for contesting political ideologies. Cambridge Journal of Economics, v. 14, n. 4, p. 375-393, 1990.

BLUNDELL, R.; BOND, S. Initial conditions and moment restrictions in dynamic panel data models. Journal of econometrics, v. 87, n. 1, p. 115-143, 1998.

BRESSER-PEREIRA, L. C. A tendência à sobreapreciação da taxa de câmbio no Brasil. In:__ Crise global e o Brasil. Rio de Janeiro: Editora da Fundação Getúlio Vargas, 2010.

. Dutch disease and its neutralization: a Ricardian approach. Revista de Economia $\overline{\text { Política }}$, v. 28, n. 1, p. 47-71, jan./mar. 2008.

BRESSER-PEREIRA, L. C.; MARCONI, N. Existe doença holandesa no Brasil? In: BRESSERPEREIRA (Org.). Doença holandesa e indústria. Rio de Janeiro: Editora da Fundação Getulio Vargas, 2008.

CENTRE D'ÉTUDES PROSPECTIVES ET D'INFORMATIONS INTERNATIONALES. Economie mondiale: la montée des tension. Paris: Economica, 1983.

CIMOLI, M.; FLEITAS, S.; PORCILE, G. Technological intensity of the export structure and the real exchange rate. Economics of Innovation and New Technology, v. 22, n. 4, p. 353-372, 2013. 
DOLLAR, D. Outward-oriented developing economies really do grow more rapidly: evidence from 95 LDCs, 1976-1985. Economic Development and Cultural Change, v. 40, n. 3, p. 523-544, 1992.

DOSI, G.; PAVITT, K.; SOETE, L. The economics of technological change and international trade. California: Harvester Wheatsheaf, 1990.

DUTT, A. K. Growth, distribution, and technological change. Metroeconomica, v. 38, n. 2, p. 113-134, 1984.

Press, 1990.

Growth, Distribution, and uneven development. Cambridge: Cambridge University

EASTERLY, W. The lost decades: developing countries' stagnation in spite of policy reform 1980-1998. Washington, DC: World Bank, 2001.

FRENKEL, R. Real exchange rate and employment in Argentina, Brazil, Chile and Mexico. Iktisat Isletme ve Finans, v. 19, n. 223, p. 29-52, 2004.

FUNDAÇÃO CENTRO DE ESTUDOS DO COMÉRCIO EXTERIOR. FuncexData. Disponível em: <http://www.funcexdata.com.br/indicadores.asp>. Acesso em: 16 ago. 2013.

FUNDO MONETÁRIO INTERNACIONAL. World Economic Outlook Database. Disponível em: <http://www.imf.org/external/pubs/ft/weo/2013/01/weodata/index.aspx > . Acesso em: 18 ago. 2013.

FURTADO, C. Elementos de uma teoria do subdesenvolvimento. In: BIELSCHOWSKY, R. (Org.). Cinquenta anos de pensamento na Cepal. Rio de Janeiro: Record, 1961.

GALA, P. Real exchange rate levels and economic development: theoretical analysis and empirical evidence. In: ENCONTRO NACIONAL DE ECONOMIA, 35., 2007, Recife. Proceedings... Recife: ANPEC, 2007.

GALA, P.; LIBÂNIO, G. A. Taxa de câmbio, poupança e produtividade: impactos de curto e longo prazo. Economia e Sociedade, Campinas, v. 20, n. 2, p. 229-242, ago. 2011.

IBGE. Comissão Nacional de Classificação (CONCLA). Disponível em: < https://concla.ibge. gov.br/classificacoes/por-tema/atividades-economicas>. Acesso: 14 ago. 2013.

Contas Nacionais Trimestrais (CNT). Disponível em: <https://sidra.ibge.gov.br/ pesquisa/cnt/tabelas >. Acesso em: 14 ago. 2013.

. Pesquisa Industrial Anual - Empresa (PIA). Disponível em: < https://sidra.ibge.gov.br/ pesquisa/pia-empresa/tabelas>. Acesso em: 14 ago. 2013.

. Pesquisa Industrial Mensal - Produção Física (PIM-PF). Disponível em: < https:// sidra.ibge.gov.br/pesquisa/pim-pf-brasil/tabelas >. Acesso em: 14 ago. 2013.

Pesquisa Mensal de Comércio (PMC). Disponível em: < https://sidra.ibge.gov.br/ pesquisa/pmc/tabelas >. Acesso em: 14 ago. 2013. 
INSTITUTO DE PESQUISA ECONÔMICA APLICADA. Ipeadata: base de dados econômicos e financeiros mantida pelo Instituto de Pesquisa Econômica Aplicada. Disponível em: <http://www.ipeadata.gov.br>. Acesso em: 14 ago. 2013. 2009 .

. O mapa das exportações. Revista Desafios do Desenvolvimento, n. 52, p. 23-33, jul.

KALDOR, N. Causes of the slow rate of economic growth in the United Kingdom. In: Further essays on economic theory. New York: Holmes $\mathcal{E}$ Meier, 1966.

LAFAY, G. Mesure dês avantages comparatifs révélés. Économie Perspective Internationale, v. 41, n. 1, p. 12-15, 1990.

LALL, S. Competitiveness, technology and skills. Cheltenham: Edward Elgar, 2001.

. The technological structure and performance of developing country manufactured exports, 1985-98. Oxford Development Studies, v. 28, n. 3, p. 337-369, 2000.

LAURSEN, K. Revealed comparative advantage and the alternatives as measures of international specialization. Copenhagen: Danish Research Unit for Industrial Dynamics, 1998. (Working paper, n. 98-30).

LEWIS, A. W. Economic development with unlimited supply of labor. In: AGARWALA; SINGH (Org.). The economics of underdevelopment. New York: Oxford University Press, 1954.

MORENO-BRID, J. C. Capital flows, interest payments and the balance-of-payments constrained growth model: a theoretical and an empirical analysis. Metroeconomica, v. 54, n. 2, May 2003.

OCAMPO, J. A. The quest for dynamic efficiency: Structural dynamics and economic growth in developing countries. In: vulnerability. Stanford. 2005. . Beyond reforms: structural dynamics and macroeconomic

OCAMPO, J. A.; PARRA, M. A. The dual divergence: growth successes and collapses in the developing world since 1980. Department of Economic and Social Affairs, June 2006. (Working Paper, n. 24).

OREIRO, J. L. C.; NAKABASHI, L.; SOUZA, G. A economia brasileira puxada pela demanda agregada. Revista de Economia Política, v. 30, n. 4, p. 581-603, 2010.

OREIRO, J. L.; BASÍLIO, F. A.; SOUZA, G. J. Acumulação de capital, taxa real de câmbio e catching-up: teoria e evidência para o caso brasileiro. In: FÓRUM DE ECONOMIA DE SÃO PAULO, 10., 2013, São Paulo. Anais... São Paulo: Fundação Getúlio Vargas, 2013.

ORGANIZATION FOR ECONOMIC COOPERATION AND DEVELOPMENT. Structural adjustment and economic performance. Paris: OECD, 1987.

PALMA, G. Flying-geese and lame ducks: regional powers and the different capabilities of Latin America and East Asia to 'demand-adapt' and 'supply-upgrade' their export productive capacity. Cambridge: University of Cambridge, 2004. 
PASINETTI, L. Structural change and economic growth: a theoretical essay on the dynamics of the wealth of nations. Cambridge: Cambridge University Press, 1981.

. Structural economic dynamics: a theory of the economic consequences of human learning. Cambridge: Cambridge University Press, 1993.

PAVITT, K. Sectoral patterns of technical change: towards a taxonomy and a Theory. Research Policy, v. 13, n. 6, p. 343-373. 1984.

POPOV, V.; POLTEROVICH, V. Accumulation of foreign exchange reserves and long term growth. Moscow: New Economic School, 2002. Unpublished paper.

PREBISCH, R. O desenvolvimento econômico da América Latina e seus principais problemas. In: BIELSCHOWSKY, R. (Org.). Cinquenta anos de pensamento na Cepal. Rio de Janeiro: Record, 1949.

RAPETTI, M.; SKOTT, P.; RAZMI, A. The real exchange rate and economic growth: are developing countries different? International Review of Applied Economics, v. 26, n. 6, p. 735-753, 2012.

RAZIN, O.; COLLINS, S. Real exchange rate misalignment and growth, forthcoming. In: RAZIN, A.; SADKA, E. (Ed.). International economic integration: public economics perspectives. Cambridge: Cambridge University Press, 1997. (Working paper, n. 6147)

REINERT, E. S. The role of the state in economic growth. Journal of Economic Studies, v. 26, n. 4/5, p. 268-326, 1999.

RIBEIRO, E. P.; PEREIRA, F. K. R. Criação e destruição de emprego na indústria e os efeitos do câmbio e da abertura comercial. Economia Aplicada, São Paulo, v. 10, n. 3, p. 325-348, jul./set. 2006.

RODRIK, D. Growth strategies. Cambridge: Harvard University, 2004.

RODRIK, D. The real exchange rate and economic growth. Brookings Papers on Economic Activity, v. 2, p. 365-412, 2008.

ROSENSTEIN-RODAN, P. N. Problems of industrialization in Eastern Europe and SouthEastern Europe. Economic Journal, v. 53, n. 210/211, p. 202-211, Jun. 1943.

ROWTHORN, R. Demand, real wages and economic growth. London: Thames Polytechnics, 1981.

TAYLOR, L. A stagnationist model of economic growth. Cambridge Journal of Economics, v. 9, n. 4, p. 383-403, 1985.

THIRLWALL, A. P. A natureza do crescimento econômico: um referencial alternativo para compreender o desempenho das nações. Brasília, DF: Ipea, 2005.

. The balance of payments constraint as an explanation of international growth rate differences. Quarterly Review, v. 32 n. 128, p. 45-53, Mar. 1979. 
THIRLWALL, A. P.; HUSSAIN, M. The balance of payments constraint, capital flows and growth rate differences between developing countries. Oxford Economic Papers, Oxford University Press, v. 34, n. 3, p. 498-510, Nov. 1982.

UNITED NATIONS CONFERENCE ON TRADE AND DEVELOPMENT. International Trade Statistics. Disponível em: < http://unctadstat.unctad.org/wds/ReportFolders/reportFolders. aspx> . Acesso: 20 ago. 2013.

WILLIAMSON, J. Exchange rate policy and development, presented in initiative for policy dialogue task force on macroeconomics. New York: Columbia, 2003.

\section{Apêndice A - Classificação das atividades industriais por intensidade de Fatores Específicos}

\begin{tabular}{l:l}
\hline \multicolumn{1}{c}{ CNAE 1.0 (até 2007) } & \multicolumn{1}{c}{ CNAE 2.0 } \\
\hline \multicolumn{1}{c}{ Intensiva em Recursos Naturais } \\
\hline 10 Extração de carvão mineral & 05 Extração de carvão mineral \\
11 Extração de petróleo e serviços relacionados & 06 Extração de petróleo e gás natural \\
13 Extração de minerais metálicos & 07 Extração de minerais metálicos \\
14 Extração de minerais não metálicos & 08 Extração de minerais não metálicos \\
15 Fabricação de produtos alimentícios e be- & 09 Atividades de apoio à extração de mi- \\
bidas & nerais \\
16 Fabricação de produtos do fumo & 10 Fabricação de produtos alimentícios \\
19.1 Curtimento e outras preparações de couro & 11 Fabricação de bebidas \\
20 Fabricação de produtos de madeira & 12 Fabricação de produtos do fumo \\
21.1 Fabricação de celulose e outras pastas & 15.1 Curtimento e outras preparações de \\
para a fabricação de papel & couro \\
21.2 Fabricação de papel, papelão liso, cartoli- & 16 Fabricação de produtos de madeira \\
na e cartão & 17.1 Fabriçãão de celulose e outras pastas \\
23 Fabricação de coque, refino de petróleo, & para a fabricação de papel \\
elaboração de combustíveis nucleares e produ- & 17.2 Fabricação de papel, cartolina e \\
ção de álcool & papel-cartão \\
26 Fabricação de produtos de minerais não & 19 Fabricação de coque, de produtos deri- \\
metálicos (excl. 26.1 e 26.4) & vados do petróleo e de biocombustíveis \\
27.4 Metalurgia de metais não ferrosos & 23 Fabricação de produtos de minerais não \\
37 Reciclagem & metálicos (excl. 23.1 e 23.4) \\
& 24.4 Metalurgia dos metais não ferrosos \\
\hline
\end{tabular}

\section{Intensivas em Trabalho}

17 Fabricação de produtos têxteis

18 Confecção de artigos do vestuário e acessórios

19 Preparação de couros e fabricação de artefatos de couro, artigos de viagem e calçados (excl. 19.1)

28 Fabricação de produtos de metal - exceto máquinas e equipamentos

36 Fabricação de móveis e indústrias diversas
13 Fabricação de produtos têxteis

14 Confecção de artigos do vestuário e acessórios

15 Preparação de couros e fabricação de artefatos de couro, artigos para viagem e calçados (excl. 15.1)

25 Fabricação de produtos de metal, exce-

to máquinas e equipamentos

31 Fabricação de móveis

32 Fabricação de produtos diversos 


\section{Intensivas em Economias de Escala}

21.3 Fabricação de embalagens de papel ou papelão

21.4 Fabricação de artefatos diversos de papel, papelão, cartolina e cartão

22 Edição, impressão e reprodução de gravações

24 Fabricação de produtos químicos (excl.

24.5)

25 Fabricação de artigos de borracha e plástico

26.1 Fabricação de vidro e de produtos do vidro

26.4 Fabricação de produtos cerâmicos

27 Metalurgia básica (excl. 27.4)

34 Fabricação e montagem de veículos automotores, reboques e carrocerias

35 Fabricação de outros equipamentos de transporte (excl. 35.3)
17.3 Fabricação de embalagens de papel, cartolina, papel-cartão e papelão ondulado 17.4 Fabricação de produtos diversos de papel, cartolina, papel-cartão e papelão ondulado

18 Impressão e reprodução de gravações

20 Fabricação de produtos químicos

22 Fabricação de produtos de borracha e

de material plástico

23.1 Fabricação de vidro e de produtos do vidro

23.4 Fabricação de produtos cerâmicos

24 Metalurgia (excl. 24.4)

29 Fabricação de veículos automotores, reboques e carrocerias

30 Fabricação de outros equipamentos de transporte, exceto veículos automotores (excl. 30.4)

\section{Intensivas em Tecnologia Diferenciada}

29 Fabricação de máquinas e equipamentos 31 Fabricação de máquinas, aparelhos e materiais elétricos

33.2 Fabricação de aparelhos e instrumentos de medida, teste e controle - exceto equipamentos para controle de processos industriais 33.3 Fabricação de máquinas, aparelhos e equipamentos de sistemas eletrônicos dedicados à automação industrial e controle do processo produtivo

33.4 Fabricação de aparelhos, instrumentos e materiais ópticos, fotográficos e cinematográficos

33.5 Fabricação de cronômetros e relógios 33.9 Manutenção e reparação de equipamentos médico-hospitalares, instrumentos de precisão e ópticos e equipamentos para automação industrial
26.5 Fabricação de aparelhos e instrumentos de medida, teste e controle; cronômetros e relógios

26.7 Fabricação de equipamentos e instrumentos ópticos, fotográficos e cinematográficos

26.8 Fabricação de mídias virgens, magnéticas e ópticas 27 Fabricação de máquinas, aparelhos e materiais elétricos

28 Fabricação de máquinas e equipamentos

33 Manutenção, reparação e instalação de máquinas e equipamentos 


\section{Intensivas em Ciência ou PED}

24.5 Fabricação de produtos farmacêuticos 30 Fabricação de máquinas para escritório e equipamentos de informática

32 Fabricação de material eletrônico e de aparelhos e equipamentos de comunicações 33.1 Fabricação de aparelhos e instrumentos para usos médicos-hospitalares, odontológicos e de laboratórios e aparelhos ortopédicos 35.3 Construção, montagem e reparação de aeronaves
21 Fabricação de produtos farmoquímicos e farmacêuticos

26.1 Fabricação de componentes eletrônicos

26.2 Fabricação de equipamentos de informática e periféricos

26.3 Fabricação de equipamentos de comunicação

26.4 Fabricação de aparelhos de recepção, reprodução, gravação e amplificação de áudio e vídeo

26.6 Fabricação de aparelhos eletromédicos e eletroterapêuticos e equipamentos de irradiação

30.4 Fabricação de aeronaves

Fonte: Elaboração própria com base em CNAE 2.0 e 1.0 (IBGE-CONCLA), Pavitt (1984) e Organization for Economic Cooperation and Development (1987).

Recebido em: 10/08/2015. Aceito em: 03/01/2017. 